\title{
Maternal IgA2 Association with Colostrum Microbiota Contributes to Bacteria Establishment During Intestinal Colonization in the Neonate.
}

\section{Leopoldo Santos Argumedo ( $\square$ lesantos@cinvestav.mx )}

CINVESTAV IPN: Centro de Investigacion y de Estudios Avanzados del Instituto Politecnico Nacional https://orcid.org/0000-0002-4772-0713

\section{Erick Sánchez-Salguero}

CINVESTAV IPN: Centro de Investigacion y de Estudios Avanzados del Instituto Politecnico Nacional Héctor Guzmán-Aquino

CINVESTAV IPN: Centro de Investigacion y de Estudios Avanzados del Instituto Politecnico Nacional

María Fernanda de la Borbolla-Cruz

CINVESTAV IPN: Centro de Investigacion y de Estudios Avanzados del Instituto Politecnico Nacional

Víctor Contreras-Vargas

hospital 10 de octubre issste

Karina Corona-Cervantes

CINVESTAV IPN: Centro de Investigacion y de Estudios Avanzados del Instituto Politecnico Nacional

Alberto Piña-Escobedo

CINVESTAV IPN: Centro de Investigacion y de Estudios Avanzados del Instituto Politecnico Nacional Jaime García-Mena

CINVESTAV IPN: Centro de Investigacion y de Estudios Avanzados del Instituto Politecnico Nacional

\section{Research}

Keywords: IgA2, IgA1, Microbiota, Colostrum, Meconium, Maternal transfer, IgA-seq

Posted Date: April 6th, 2021

DOl: https://doi.org/10.21203/rs.3.rs-378804/v1

License: (c) (i) This work is licensed under a Creative Commons Attribution 4.0 International License. Read Full License 


\section{Abstract}

Background: Microbiota colonization during labor and through the first meals contributes to immune maturation and development of the newborn. Mother provides probiotics and prebiotics factors through colostrum and maternal milk to shape the first neonatal microbiota. Previous works have reported that immunoglobulin A $(\lg A)$ secreted in colostrum is coating a fraction of maternal microbiota.

Methods: Thus, to better characterize the IgA-associated microbiota, we used flow cytometry coupled with 16S rDNA gene sequencing (IgA-Seq) in human colostrum and neonatal feces. We identified IgA-bound bacteria ( $\lg \mathrm{A}+$ ) and characterized its diversity to elucidate possible role of IgA subclasses during neonatal bacterial colonization of the colon.

Results: We found that IgA2 in the colostrum has an active role during microbiota colonization. Colostrum IgA2 is mainly associated with Bifidobacterium, Lactobacillus, and Bacteroidetes genera. This association seems to give these bacteria an advantage during their establishment since metabolic pathways related to epithelial adhesion and carbohydrate consumption are enriched within fecal IgA2+ microbiota. Association with specific bacteria could be explained since IgA2 recognizes common antigens expressed on surfaces among bacteria genera.

Conclusions: Our data suggest a specific targeting of commensal bacteria by IgA2 revealing a specialized function of IgA microbiota association during neonatal intestinal colonization during the first days of life.

\section{Background}

Different studies have evaluated the importance of acquiring good microbiota in early life [1, 2]. These processes are regulated by different conditions like birth route [3], lactation mode [4], mother's diet, and intestine maternal microbiota [5]. Colostrum, the first secretion during lactation, contains factors that contribute to the defense and immune stimulation for the newborn and, at the same time, it is an essential source of microorganisms for microbiota establishment in the neonate [6, 7].

These microorganisms live along the breast duct [3]. Their composition and microbial variability are high near the nipple, decrease along branched ducts to mammary acinus. Its composition depends on the diet during pregnancy, lactation, type of delivery, and lactation span $[8,9]$.

Colostrum microbiota composition remains stable in complexity and diversity during the first days postpartum [10]. Surprisingly, some of these bacterial genera, from an epidemiological point of view, have potentially pathogenic properties; and are a stimulus and signal for the development and maturation of the newborn's intestinal mucosa [11]. Early interaction with microorganisms appears to play an essential role in developing the infant immune system, establishing a tolerance response to these bacterial species $[12,13,14]$. 
At the same time, human colostrum is the primary source of maternal IgA. Once transferred to the newborn, IgA plays a crucial role in gastrointestinal tract protection through immune exclusion against pathogens [15]. However, it was shown that a significant fraction of commensal bacteria are associated with IgA [16] in homeostatic conditions. These antibodies recognize and associate with resident microbiota in acini, duct, and nipple skin during colostrum ejection. The transit of maternal IgA through the newborn gastrointestinal tract and its recovery in the newborn's feces have been documented [17].

IgA in the gastrointestinal tract neutralizes pathogenic microorganisms and directly regulates microbiota composition $[18,19,20]$, suggesting that maternal milk IgA-microbiota impacts bacteria intestine colonization in the newborn [21, 22]. This paradoxical function of the IgA has been poorly analyzed. Previous studies in mice have suggested a possible explanation for this seemingly dual function. In one hand, IgA produced by T-dependent responses (against protein antigens) is associated with potential pathogens, while on the other hand IgA made by T-independent stimulation (mainly against carbohydrates antigens) recognizes species of commensal microbiota [23, 24].

Human IgA has two subclasses, IgA1 and IgA2, with well-defined properties and structures [25]. In a recent study, Sterlin and colleagues described that most commensal IgA-decorated bacteria present in adult fecal samples are bound to the IgA2 subclass. These data suggest that this subclass would play a role in regulating commensal bacteria under homeostatic conditions in the intestinal tract [26]. Ladjeva et al. described an individual variability in specificity between colostrum IgA1 and IgA2 subclasses. IgA1 recognizes protein antigens (bovine gamma globulin, lactoglobulin, tetanic toxoid, Streptococcus mutans antigens I and II, and influenza virus vaccine). In sharp contrast, IgA2 was associated with Escherichia coli lipopolysaccharide (LPS), Streptococcus pneumoniae polysaccharide, Haemophilus influenzae type b hemagglutinin [27]. Work from our laboratory found that specific IgA1 levels of antigen increase in women with prior vaccination with tetanus toxoid (protein antigen), while antigen-specific IgA2 increased, predominantly, in mothers with pneumococcal polysaccharide vaccination [28]. However, the microbiota distribution associated with IgA subclasses in colostrum and their role in transferring maternal microbiota to the newborn has not been described.

In this work, we analyzed colostrum from mothers and fecal samples from neonates (before and after feeding with colostrum) to compare microbiota composition. Our results demonstrated specific targeting of commensal bacteria by $\lg \mathrm{A} 2$ and revealed a specialized IgA-associated microbiota function during the newborn's intestine colonization during the first days of life.

\section{Methods}

\section{Design and type of study}

This study is an analytical, observational, prospective, and longitudinal. The population was selected through a simple random process. Clinically healthy women were recruited at Hospital Regional $1^{\circ}$ de Octubre (HR $1^{\circ} \mathrm{Oct}$ ) Instituto de Seguridad y Servicio Social para Los Trabajadores del Estado (ISSSTE). All the activities detailed in this protocol have the approval of the Research and Bioethics Committee of 
HR $1^{\circ}$ Oct (090201/14.1/086/2017). Sociodemographic, anthropometric, and clinical data (education, occupation, maternal and gestational age, and type of delivery) were recorded. Two to three $\mathrm{mL}$ of colostrum, and 0.5-2 g fecal samples, from one hundred eighty mother-newborn binomials were collected. The sample size was determined by a non-probabilistic convenience sampling, considering new delivery mothers between November 2017 and July 2019.

\section{Selection criteria}

Inclusion criteria. Women between 25 and 30 years old, with a full-term pregnancy (38-42 weeks of gestation), due to physiological delivery (F), who has regularly attended their medical care to monitor their pregnancy, with the delivery of the unique product and agreeing to participate in this project.

Exclusion criteria. Women unable or unwilling to breastfeed, who reported chronic degenerative disease under drug, hormonal, or antibiotic treatment were omitted. Women who reported alcohol and smoking during pregnancy or decided not to continue in the study, o reported an acute illness in the last three weeks before delivery were also omitted.

\section{Sampling}

Before delivery, patients who agreed to participate in the study received informed consent, which they read and signed following the Helsinki treaty, General Health Law, and Hospital ethics committee. They were given a questionnaire, which they filled out with their general data and clinical information. Data reported by patients were corroborated with their medical history files from the hospital archive. Samples were taken, under aseptic conditions, with sterile material and qualified medical personnel. Meconium was obtained during labor and in the first evacuation of newborns. Colostrum samples were obtained following the procedures described in the milk extraction technique protocol in the lactation clinics of Children's and General Hospitals, within the first hours postpartum after cleaning the nipple and areola area with physiological saline solution and sterile gauze. Special care was taken to ensure infants were exclusively breastfed during their permanence in the hospital. Two stool samples from the neonates were requested: before and after three days the neonates were fed by their mother. As a control of maternal milk factors transference process, pasteurized maternal milk samples from the Hospital's Milk Bank were used. This pasteurized milk (Pasteurized) is a supplementary feeding option recommended when breastfeeding is not feasible; for example, ablactation, maternal disease, or impediment due to drug intake. This pasteurized sample is prepared with volumes of donor mothers less than seven days postpartum in Hospital Milk Bank, which is pasteurized $\left(63^{\circ} \mathrm{C}\right.$ for $30 \mathrm{~min}$ ) and delivered to the neonate [29]. After treatment, a $2 \mathrm{~mL}$ sample was taken. Finally, sampling of meconium and feces from a group of neonates fed with pasteurized milk was included $(n=8)$ according to the pediatrician's indications. Samples were kept at $4^{\circ} \mathrm{C}$ for their transfer to the laboratory, to be processed within the first 20 minutes after sampling.

\section{Phase separation}


For separation, the methodology applied in this work was previously reported by Bunker et al. [23]. Briefly, $500 \mathrm{mg}$ meconium/stool samples were taken and resuspended in $2 \mathrm{~mL}$ of sterile phosphate buffer saline (PBS) (Cat\# P4417-100TAB, Sigma-Aldrich ${ }^{\circledR}$, St Louis, Missouri, USA). Colostrum, meconium, and stool samples were treated with protease inhibitor cocktail (Cat \#P8465, Sigma-Aldrich ${ }^{\circledR}$ ) $1 \%$ with $0.01 \%$ sodium azide $\left(\mathrm{NaN}_{3}\right)$ (Cat\# S2002, Sigma-Aldrich $\left.{ }^{\circledR}\right)$ following manufacturer specifications. Samples were centrifuged at $400 \mathrm{~g}$ for 10 minutes at $4^{\circ} \mathrm{C}$, and three phases were obtained: a) a top lipid phase, b) a middle aqueous phase, and c) cellular components in the bottom. The aqueous phase was separated, trying not to drag the surface phase's remains or the cellular components. These top and bottom phases were discarded. The aqueous phase was centrifugated at $8,000 \mathrm{~g}$ for 30 minutes at $4^{\circ} \mathrm{C}$ (Allegra X-22 Series Beckman Coulter ${ }^{\circledR}$ USA centrifuge). Two phases were obtained, supernatant and pellet. The supernatant was stored in aliquots at $-70^{\circ} \mathrm{C}$ for the determination of free immunoglobulins by ELISA. The pellet was processed to separate the bacteria associated with $\lg A$ subclasses $(\lg A 1+$ and $\lg A 2+)$ or free fraction ( $\lg A-)$.

\section{ELISA Immunoglobulin quantification assay}

The method was previously reported by [30]. Briefly, flat-bottom 96-well polystyrene plates (Thermo scientific ${ }^{\circledR}$ MaxiSorp USA) were sensitized with $100 \mu \mathrm{L}$ of mouse monoclonal antibody 7A09 anti-human light chain (Cat\# ab1942, Abcam ${ }^{\circledR}$ ), at $1 \mu \mathrm{g} / \mathrm{mL}$ in PBS. The plates were incubated 12 hours at $4^{\circ} \mathrm{C}$. Blocking was carried out with $200 \mu \mathrm{L}$ per well of BSA (Cat\# A1933, Sigma-Aldrich $\AA$ ) $5 \%$ in PBS with Tween 20 (Cat\# P2287, Sigma-Aldrich ${ }^{\circledR}$ ) 0.05 \% (PBST), 90 min at $25^{\circ} \mathrm{C}$. For the standard curve, $100 \mu \mathrm{L}$ of the standard solutions prepared from commercial reagents of purified human immunoglobulins were added per well: human IgA1 protein (Cat\# ab91020, Abcam ${ }^{\circledR}$ ) and human IgA2 protein (Cat\# ab91021, Abcam ${ }^{\circledR}$ ) in PBS; for an incubation time of 2 hours at $37^{\circ} \mathrm{C}$. For the detection of IgA1, a biotin-coupled anti-human IgA1 Fc region mouse monoclonal antibody was added (Cat\# ab99796, Abcam ${ }^{\circledR}$ ), a dilution of 1:2,000. For detection of IgA2, a biotin-coupled anti-human IgA2 Fc region mouse monoclonal antibody was added (Cat\# ab128731, Abcam ${ }^{\circledR}$ ), a dilution of 1:1,000. Finally, $100 \mu \mathrm{L}$ of a 1:5,000 dilution of streptavidin-horseradish peroxidase (HRP) complex (Cat\# ab7403, Abcam ${ }^{\circledR}$ ) were added per well, and it was incubated 1 hour at $37^{\circ} \mathrm{C}$. For development, $100 \mu \mathrm{L}$ per well of $3^{\prime} 3$ "-5-5-tetramethylbenzidine (TMB) with hydrogen peroxide $\left(\mathrm{H}_{2} \mathrm{O}_{2}\right)$ (Cat\# ab171523, Abcam ${ }^{\circledR}$ ) was incubated $10 \mathrm{~min}$. The reaction was stopped with the addition of $100 \mu \mathrm{L}$ of $0.2 \mathrm{M}$ sulfuric acid $\left(\mathrm{H}_{2} \mathrm{SO}_{4}\right)$ (Cat\# 7664-93-9 JT Baker®, Fisher Scientific, USA). The plates were read in the spectrophotometer (Sunrise absorbance reader, Tecan's Magellan $\AA$ universal reader) at $450 \mathrm{~nm}$. The analysis was performed using GraphPad Prism $\circledast$ version 7.00 (GraphPad® Software, La Jolla, California USA).

\section{Separation of bacteria into $\lg A 1+$ and $\lg A 2+$ fractions}

Pellets were processed to separate bacteria fractions according to their association with IgA subclasses, as previously reported [23]. The pellets were incubated for fifteen minutes at room temperature with $0.25 \%$ BSA, 5\% Calf Fetal Serum (CFS) (Cat\# 26140, Thermo Fisher ${ }^{\circledR}$ ), and 2 mM Ethylenediaminetetraacetic acid (EDTA) (Cat\# 6381-92-6, JT Baker ${ }^{\circledR}$ ) in PBS. Subsequently, they were 
washed five times with PBS and resuspended in a final volume of $1 \mathrm{~mL}$. Total sample volume was separated into four sterile tubes: a) total bacteria, b) IgA- bacteria, c) IgA1+ bacteria, and d) IgA2+ bacteria. Separation of the IgA-associated bacterial fractions was executed with biotinylated antibodies to human IgA subclasses: anti-human IgA1 (Cat\# ab99796, Abcam ${ }^{\circledR}$ ) at a dilution of 1:2500 and antihuman IgA2 (Cat\# ab128731, Abcam $\AA$ ) at a dilution of 1:2,000. Subsequently, streptavidin complexes associated with Allophycocyanin-Cy7 (APCy7) (Cat\# 405208, Biolegend ${ }^{\circledR}$, San Diego, CA, USA) or Fluorescein isothiocyanate (FITC) (Cat\# 405201, Biolegend $\AA$ ) were added. Finally, magnetic microbeads decorated with mouse monoclonal antibodies specific to each fluorochrome: anti-FITC microbeads (Cat\# 130-048-701 Miltenyi Biotec Inc., Sunnyvale, CA, USA) or anti Cy7 microbeads (Cat\# 130-091-652 Miltenyi Biotec Inc.) were added. A magnet system for cell separation (Cat\# 18,000 EasySep ${ }^{\mathrm{TM}}$ Magnet, Stem Cell Technologies $\AA$, Canada), positive selection was carried out for bacteria decorated with IgA subclasses. The purity of $\lg A 1+$, IgA2+, and IgA- bacterial fractions was verified in the CytoFLEX flow cytometer (Cat\# B53000 Beckman Coulter ${ }^{\circledR}$ ) and analyzed with CytExpert Software (Beckman Coulter $\left.{ }^{\circledR}\right)$.

Two aliquots of $10 \mu \mathrm{L}$ from each bacterial fraction were separated and resuspended in $100 \mu \mathrm{L}$ of PBS to: a) quantify bacteria using a Bacteria Counting Kit (\#Cat B7277, Thermo scientific ${ }^{\circledR}$ CA, USA) and b) evaluate viability using a Bacterial Viability Assay Kit (Cat\# ab189618, Abcam®, Cambridge UK); in according to the supplier's instructions. In briefly, for quantification protocol, $1 \mu \mathrm{L}$ of SYTO ${ }^{\circ} \mathrm{BC}$ bacteria stain to each aliquot and incubated at $37^{\circ} \mathrm{C}$, for 5 minutes and washed three times with PBST. Finally, 10 $\mu \mathrm{L}$ of the microsphere suspension was added to the stained cell preparation, for $10 \mathrm{~min}$; washed with PBST for three times and analyze in flow cytometer. For viability assay, $3 \mu \mathrm{L}$ of a mixture with equal volumes of $\mathrm{SYTO}{ }^{\circledR} 9$ and propidium iodide $(\mathrm{PI})$ was added for each milliliter of the bacterial suspension, incubated at room temperature in the dark for 15 minutes. Finally, mixture was washed three times with PBST and analyze in flow cytometry.

\section{Enzyme protease kinetic assay}

To demonstrate that loss of IgA1 signal was due to bacterial enzymatic degradation activity, we used human IgA1 protein (Cat\# ab91020, Abcam ${ }^{\circledR}$ ), at $10 \mathrm{mg} / \mathrm{mL}$ or human IgA2 protein (Cat\# ab91021, Abcam $\left.{ }^{\circledR}\right)$, at $12 \mathrm{mg} / \mathrm{mL}$ diluted in PBS. These proteins were to interact with $100,000 \mathrm{lgA} 1+$ bacteria fraction or $200,000 \lg A 2+$ bacteria fraction isolated from human colostrum; at $4^{\circ} \mathrm{C}$ (as temperature control) or $37^{\circ} \mathrm{C}$ and with or without protease inhibitor cocktail (Cat \#P8465, Sigma-Aldrich $\circledast$ ); for two hours. At each 20 minutes interval, we took an aliquot and were frozen until the moment of ELISA quantification assay, as described below.

\section{Extraction and purification of Deoxyribonucleic acid (DNA)}

DNA was obtained from bacteria fractions with Favor Prep Milk Bacterial DNA Extraction Kit (Cat\# FASTI 001-1 Favorgen Qiagen ${ }^{\circledR}$, Cambridge, UK) and QIAmp DNA Stool Mini Kit (Cat\# 51306 Qiagen $\left.{ }^{\circledR}\right)$. The concentration and purity of DNA were determined by absorbance ratio 260/280 using NanoDrop Lite Spectrophotometer (Cat\# ND-1000 Thermo Scientific $\left.{ }^{\circledR}\right)$. DNA quality was evaluated by electrophoresis in 
0.5\% agarose gel, using Tris-Borate-EDTA (TBE), at 90 Volts for 50 min. The gels were stained with 0.80 $\mu \mathrm{L}$ of Midori Green dye advanced (Cat\# CLS-1909-G Nippon Genetics® Europe, Dueren, Germany) dilution 1:15. The gels were documented by Chemidoc ${ }^{\mathrm{TM}}$ XRS + System Molecular Imager Gel (Cat\# 170-8070 Bio$\operatorname{Rad}{ }^{\circledR}$, Hercules CA, USA). As positive control we used $10 \mathrm{ng} / \mathrm{uL}$ of DNA extracted from an Escherichia coli strain (E coli SK100 19p EJ01).

\section{Amplification of the V3 region of 16S rDNA}

An approximately 281 base pair (bp) fragment corresponding to the hypervariable region 3 (V3) of the bacterial 16S ribosomal DNA (16Sr DNA) was amplified from each DNA sample. Universal primers amplify the V3 polymorphic region of the rDNA gene, V3-341F (CCTACGGGAGGCAGCAG) and V3-518R (ATTACCGCGGCTGCTGG), were used, containing the adapter and barcode sequences for multiple samples massive sequencing. Amplification was carried out by end-point polymerase chain reaction (PCR) in Applied Biosystems ${ }^{\circledR} 2720$ Thermal Cycler (ThermoFisher Scientific ${ }^{\circledR}$ ), working with a final DNA quantity of $50 \mathrm{ng}$ per reaction. Bands of interest were analyzed with the documentation system Molecular Imager ${ }^{\circledR}$ for expecting a fragment size of 281 bp. Libraries were sequenced on the lon Torrent PGM platform (Life Technologies $\AA^{\text {, }}$, Thermo Fisher Scientific $\AA$ ) using Chip 318 (Life Technologies ${ }^{\circledR}$, Thermo Fisher Scientific $\left.{ }^{\circledR}\right)$, as previously described [7]. As positive control we used a Microbial Community Standard (\#Cat D6300 Zymo Research®, Irvine CA, USA).

\section{High-throughput DNA sequencing}

Samples with specific barcodes were mixed, purified, and the final concentration of DNA in the library was quantified. Amplicons size in the library was verified using the Bioanalyzer equipment. For templates preparation, emulsion PCR spheres with lon Sphere ${ }^{\mathrm{TM}}$ Quality Control Kit (Cat\# 4468656 Life

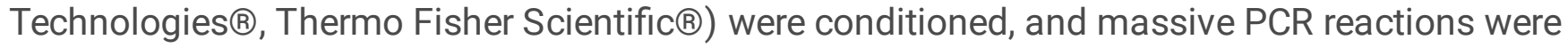
implemented in the Thermocycler system. Likewise, the spheres' quality was verified with the sample sequenced using Ion OneTouch ${ }^{\mathrm{TM}}$ system equipment (Cat\# 4474779 Thermo Fisher Scientific®) and Qubit 2.0 fluorometer Massive sequencing (Cat\# Q33327 Thermo Fisher Scientific®). Finally, samples' sequencing was performed by lon Torrent PGM ${ }^{\mathrm{TM}}$ Sequencer equipment (Cat\# A25511 Thermo Fisher Scientific®).

\section{Analysis of sequencing data}

Data were processed using Torrent Suite v4.4.3 software (Thermo Fisher Scientific®) to exclude polyclonal and low-quality sequences. The reads were assigned to the source sample employing the DNA primers system. The quality control of sequences was performed with FastQC (http://www.bioinformatics.babraham.ac.uk/projects/fastqc), and all readings were trimmed to $200 \mathrm{nt}$ in length with Trimmomatic v0.36 (http://www.usadellab.org/cms/index.php?page=trimmomatic).

Readings that passed the quality tests were exported as FASTQ files that were later transformed into FASTA files and were analyzed with QIIME pipeline software version 1.9.1. [31,32] (http:// qiime.org/). Sequences were grouped into Operational Taxonomic Units (OTUs); the taxonomic assignment was 
carried out by aligning the sequences against the 16S rDNA Greengenes database v13.8 (http://greengenes.lbl.gov/). Microbial diversity was calculated using alpha diversity (within samples) and beta diversity (among samples). Alpha diversity was estimated using different indices: observed OTUs, Chao's index, Shannon's index, and Simpson's index. These indices were determined using phyloseq and ggplot2 packages in the R environment (v3.4.4). For beta diversity, dissimilarity was estimated using UniFrac analysis (weighted and unweighted). A two-dimensional scatter plot was generated using principal coordinate analysis (PCOA). ANOSIM and Adonis statistical tests were applied. The relative abundance of the bacterial groups identified in the samples was compared by the Wilcoxon rank test using the SPSS software (version 14.0). Data analysis (group comparison) was performed by Student's t-test or by U Mann-Whitney. Values of $p<0.05$ were considered significant. Statistical operations were performed using the SPSS program (version 14.0). Linear discriminate t analysis (LDA) effect side algorithm (LEfSe v1.0) was used to identify statistically significant taxa in different groups of samples. We used LDA Fisher's linear discriminant to estimate each taxon's effect size between groups. For LDA analysis of bacteria in maternal milk samples and IgA2-associated bacteria in neonate feces fed with colostrum; thresholds of significance of 2.0 and 3.5 were used, respectively. PICRUST v1.1.1 (Phylogenetic Investigation of Communities by Reconstruction of Unobserved States) was used to predict functional metagenomes based on 16S rDNA gene data with the Kyoto Encyclopedia of Genes and Genomes (KEGG) orthologue classification database in hierarchy level 3 pathways. Statistical analysis of Taxonomic and Function software (STAMP v2.1.3) was used to determine significant differences in OTU's abundance and metabolic pathways. We performed a Source Tracker analysis to predict the origin of OTUs in each neonatal stool sample using corresponding human colostrum as a potential source to estimate the proportion of bacteria present in fecal samples attributable to the human milk. This analysis was made in the QIIME platform using Source Tracker (v0.9.5) software [33].

\section{Carbohydrates microarrays}

To identify IgA subclasses reactivity against bacteria carbohydrates, we used Glycan Array 100 for 8 sample kits (Cat\# GA-Glycan-100-1 RayBiotech ${ }^{\circledR}$ Norcross GA, USA). Slides were rinsed with PBS and blocked with $1 \%$ BSA in PBST containing $0.025 \% \mathrm{NaN}_{3}$, at room temperature for 30 min. Each subarray was stained with $40 \mu \mathrm{L}$ of each supernatant sample in 1:9 dilution with PBST containing $0.05 \% \mathrm{NaN}_{3}$ and $1 \%$ BSA. The slide was incubated in a humidified chamber at room temperature for $90 \mathrm{~min}$, and the slide was washed five times with PBST. The slide was then incubated with $40 \mu \mathrm{L}$ of secondary mouse antibody anti-human IgA2 coupled with FITC (Cat\# 9140-02 SouthernBiotech ${ }^{\circledR}$ Birmingham AL, USA) dilution

1:2500. The slide was incubated in a humidified chamber with light protection at room temperature for 30 min and washed five times, as previously described. Fluorescence signals were detected with Chemidoc $^{\text {TM }}$ XRS+ System Molecular Imager Gel (BioRad®).

\section{Analysis of IgA degradation by semi-quantitative western blotting}

A volume of colostrum fractions (Total, IgA1+, and IgA2+ microbiota) was adjusted at 10,000 bacteria per $\mathrm{mL}$. We used the purified human protein IgA1 (Cat\# ab91020 Abcam ${ }^{\circledR}$ ), and human protein IgA2 (Cat\# 
ab91021 Abcam ${ }^{\circledR}$ ) diluted in serial double dilutions in PBS for calibration curves. All bacterial fractions were lysed $30 \mathrm{~min}$ at $4{ }^{\circ} \mathrm{C}$ with RIPA buffer $(20 \mathrm{mM}$ Tris-HCl pH 7.5, $150 \mathrm{mM} \mathrm{NaCl}, 1 \mathrm{mM}$ Na2EDTA, $1 \mathrm{mM}$ EGTA, $1 \% \mathrm{NP}-40,1 \%$ sodium deoxycholate, $1 \mathrm{mM} \mathrm{Na} 3 \mathrm{VO}$, and $1 \mathrm{ug} / \mathrm{mL}$ leupeptin). The lysates were centrifuged at $4{ }^{\circ} \mathrm{C}, 15 \mathrm{~min}$ at $12,000 \mathrm{xg}$. The supernatants were separated, and proteins were quantified by the Lowry method. Samples were mixed with NuPAGE Sample Reducing Agent 10x (Cat\# NP0004 Life Technologies $\AA$ Thermo Fisher Scientific $\left.{ }^{\circledR}\right)$. The samples were separated by electrophoresis in $12 \%$ Tris$\mathrm{HCl}$ gels (Cat\# 3450009 Bio-Rad®) at $100 \mathrm{~V}$ for $90 \mathrm{~min}$ and transferred to nitrocellulose membranes 0.45 $\mu \mathrm{m}$ (Cat\# 1620115 Bio-Rad®) at $200 \mathrm{~V}$ for $60 \mathrm{~min}$. Membranes were blocked 1 hour in $5 \%$ non-fat dry milk (Cat\# 9999S Cell Signaling Technology ${ }^{\circledR}$ Danvers MA, USA) in PBST at $4^{\circ} \mathrm{C}$. After three wash cycles with PBST, the membrane was incubated overnight at $4^{\circ} \mathrm{C}$ with biotin-coupled mouse antibody antihuman IgA1 (Cat\# ab99796, Abcam ${ }^{\circledR}$ ) at 1:8,000 and a biotin-coupled anti-human IgA2 (Cat\# ab128731, Abcam ${ }^{\circledR}$ ) at 1:10,000. After that, 1: 2,000 dilution of HRP-conjugated streptavidin (Cat\# ab7403

Abcam ${ }^{\circledR}$ ) was added to the membranes and incubated $1.5 \mathrm{~h}$ at room temperature (as described above). Subsequently, labeled proteins were visualized using the ClarityTM Western ECL Substrate kit (Cat\# 1705061 BioRad $\AA$ ). The emitted chemiluminescent signal was detected with a Chemidoc ${ }^{\top M}$ XRS + System Molecular Imager Gel (BioRad $\AA$ ), and ImageJ ${ }^{\circledR}$ software (www.github.com/imagej/imagej) was used to estimate the relative amounts of protein.

\section{Serine hydroxymethyltransferase (SHMT) western blotting}

Bacterial suspensions IgA1+ and IgA2+ from human colostrum were treated as previously mentioned and mixed with NuPAGE Sample Reducing Agent 10x (Cat\# NP0004 Life Technologies ${ }^{\circledR}$ Thermo Fisher Scientific $\circledast$ ). Three control lanes were added: positive control, composed by recombinant bacterial SHMT (\#Cat LS-G78730-20 LS Bio ${ }^{\circ}$, Seattle WA, USA), negative control, composed by purified bacterial GAPDH (\#Cat NATE-1635 Creative Enzymes ${ }^{\circledR}$, Shirley NY, USA), and colostrum bacteria non-associated with IgA subclasses (IgA-). Two hundred micrograms of proteins were loaded into each lane, separated in $10 \%$ polyacrylamide electrophoresis gels (Cat\# 3450009 Bio-Rad®), and transferred to nitrocellulose membranes (Cat\# 1620115 Bio-Rad $\circledast$ ). Membranes were blocked in 5\% non-fat dry milk (Cat\# 9999S Cell Signaling Technology ${ }^{\circledR}$ Danvers MA, USA) in PBS Tween-20. After three washes with PBST $0.05 \%, 2$ $\mu \mathrm{g} / \mathrm{mL}$ of anti-SHMT hamster monoclonal IgA antibody (clone W27), previously reported [34], and was added and incubated overnight at $4^{\circ} \mathrm{C}$. The following day, the membrane was washed, and a mixture of goat anti-mouse IgA (cross-reactive with hamster immunoglobulins, Cat\# 1040-05 Southern Biotech $\AA$ ) and goat anti-bacterial GAPDH (Cat\# G8140-13H United States Biological ${ }^{\circledR}$, Salem MA, USA) (both coupled with HRP) at 1: 8,000 and 1:10,000 in PBS, respectively; were added and incubated for two hours at room temperature. Finally, the membrane was washed, and signals were visualized using the ClarityTM Western ECL Substrate kit (Cat\# 170-5061 BioRad®) and detected in Chemidoc ${ }^{\text {TM }}$ XRS+ System Molecular Imager Gel (BioRad®) and ImageJ® software (www.github.com/imagej/imagej).

\section{Statistical analysis}


Data were reported as mean \pm standard deviation (SD) or frequencies and percentages (\%). Two-tailed Student's t-test or Mann-Whitney U test was assessed to compare groups using SPSS v23.0 software (SPSS, Inc). ANOSIM and Adonis were used for category comparisons of phylogenetic distance matrices (UniFrac). Linear regression was used to know the relationship between microbiota diversity as the dependent variable and maternal and neonatal age included as covariates; $p \leq 0.05$ was considered statistically significant. The Benjamini-Hochberg $(\mathrm{BH})$ correction method was used to estimate the false discovery rate (FDR) and filter the data where a q-value $\leq$ of 0.05 was considered statistically significant.

\section{Results}

\section{The bacterial microbiota in the human colostrum are differentially decorated by IgA subclasses.}

We analyzed percentages of bacteria associated with IgA subclasses from total bacteria present in human colostrum samples (Fig. 1a) (Fig. 1b). Data showed that IgA1 decorates about $9.67 \%$ of the total bacteria present in colostrum, $21.40 \%$ are decorated with $\operatorname{lgA2}$, and $5.09 \%$ are linked to both subclasses (Fig. 1b); demonstrating that IgA subclasses have a selective recognition with colostrum bacteria.

To evaluate the colostrum IgA-microbiota association effect during bacteria establishment in neonate's intestine, we characterized and compared IgA subclasses association with bacteria in maternal colostrum (Colostrum) versus pasteurized milk (Pasteurized) samples (Figs. 1c - 1e). The data demonstrated that $\lg \mathrm{A} 2$ is more abundant than $\lg \mathrm{A} 1$ in colostrum (Fig. 1C). At the same time, IgA2 is more frequently associated with bacteria surfaces (Fig. 1d). In comparison, IgA subclasses in pasteurized milk samples were significantly reduced. Milk pasteurization denatures antibodies affecting concentration and ability to recognize antigen [35]. We observed fewer bacteria with IgA-associated on their surfaces in pasteurized milk samples (Fig. 1d) and, in general, a significantly reduced number of bacteria present in the samples (Fig. 1e). Consequently, IgA1 + and IgA2 + bacteria fractions in the pasteurized milk samples were not detected. These results strongly suggest that fresh, non-pasteurized milk is a source of IgA-decorated bacteria.

\section{Some bacteria have divergent recognition between IgA subclasses in the human colostrum.}

Bacterial microbiota relative abundances were determined at genus and family level in the fractions according to their association with IgA subclasses. Twenty bacterial genera were predominantly in colostrum, including, Clostridium, Bacteroides, Pseudomonas, Bifidobacterium, Kaistobacter, Corynebacterium, and the Enterobacteriaceae family (Fig. 2a).

As previously mentioned, bacteria fractions showed distinctive genera between IgA + subclasses fractions in human colostrum (Fig. 2a). This sharp divergence in the composition between IgA subclasses fractions composition was confirmed by LEfSe analysis (Fig. 2b). LEfSe (Linear discriminate t analysis effect size) algorithm was used to identify significant taxonomic differences in the microbiota of the groups of samples studied. LEfSe Kruskal-Wallis rank-sum test was used to detect significant characteristics of different classes, the Wilcoxon rank test, and linear discrimination analysis (LDA) to 
estimate the effect size. For analysis between the IgA subclass fractions in colostrum samples, it was found that six bacterial genera Clostridium, Streptococcus, and Staphylococcus associated with IgA1 and Bifidobacterium, Lactobacillus and Bacteroides associated with IgA2, were significantly different between fractions (Fig. 2b). Using PCoA analysis, it was determined that, although individual samples share composition between IgA fractions, most of them presented differences between them depending on IgA subclass recognition (Fig. 2c). These data demonstrate a divergent recognition of microbiota by IgA subclasses in human colostrum.

\section{IgA2 is predominantly found decorating bacteria in newborn feces of breastfed-children.}

The next step was to evaluate the microbiota present in newborn meconium and stool samples according to its association with IgA subclasses (Fig. 3a-c). As expected, bacteria associated with the IgA subclasses were not found in meconium samples (the first evacuation before breastfeeding) (Fig. 3a-b).

Breastfeed infants had the highest levels of IgA subclasses (Fig. 3d), IgA-associated microbiota (Fig. 3e), and bacterial quantity (Fig. 3f) compared to pasteurized milk-fed infants (Fig. 3d-f). Free IgA1 concentration in feces decreased in proportion to what was found in colostrum; however, IgA1-associated microbiota was neither found in breastfed-infants (Fig. 3c) nor pasteurized milk-fed samples (Fig. 3e-f). Perhaps the presence of IgA1-specific bacterial proteases in addition to intestinal lumen conditions may explain this reduction [36, 37]. IgA2 would be more resistant to these conditions. We developed a kinetic enzyme assay to explain the observed differences. The data indicated that only 20 minutes of exposition to the bacteria from either colostrum or feces is enough to decrease in $40 \%$ the amount of IgA1 (Supplementary Fig. 1). Then, as a possible explanation, IgA1 from the colostrum is degraded more rapidly by bacteria and enzymes in the newborn intestine. For that reason, it is not detected decorating the bacteria recovered from feces of breastfed infants.

Thus, the results indicated that in stool samples from neonates fed exclusively with colostrum during the first three days of life, a percentage of the recovered bacteria were exclusively associated with IgA2 (Fig. 3f). In contrast, no bacteria decorated with IgA were found in pasteurized milk-fed infants, similar to meconium samples.

\section{IgA2 + microbiota has a role on bacterial colonization of the neonate's intestine.}

Our results found that meconium has a more significant presence of the genera Pseudomonas, Staphylococcus, Clostridium, Streptococcus, and the Enterobacter family. In contrast, pasteurized milk samples showed a greater abundance of Clostridium and Pseudomonas genera. Finally, stool samples of children fed with colostrum (Clostridium, Pseudomonas, Bacteroides, Bifidobacterium, Kaistobacter, Lactobacillus, and Enterobacteriaceae family) in comparison with pasteurized milk (Clostridium, Pseudomonas, and Enterobacteriaceae family) showed significant differences in their bacterial composition (Fig. 4a). 
Observed OTUs, Chao1, Shannon, and Simpson indexes were used to analyze Alpha diversity within each sample. Total bacterial fraction showed higher bacterial richness and diversity compared with IgA subclasses ( $86 \%$ vs. $81 \%, p=0.03$ for the nonparametric Wilcoxon rank test) (Fig. 4b). Regarding the Shannon index, higher values were found for stool samples of children fed with breast milk and colostrum samples, in contrast to formula and meconium samples (Fig. 4b). As expected, meconium and pasteurized milk samples had the highest dominance indexes. For the rest of the samples, no statistically significant difference was found.

As a result, 24 taxonomic groups were significant, 6 for IgA2 + and 18 for free bacteria in feces (Fig. 4c). However, a comparison between IgA2 fraction samples from colostrum and breastfed children's feces demonstrated they were very similar. According to PCoA analysis, the data showed that meconium has a very characteristic composition. Fecal bacteria composition from children breastfed for three days is more similar to the fraction of $\lg A 2+$ bacteria in colostrum, in comparison with samples from children fed with pasteurized milk (Fig. 4d). To estimate what portion of the fecal microbiota was colostrum, we used Source Tracker analysis. The analysis suggested that $70 \%$ of intestinal microbiota had its origin in the colostrum. This microbiota is composed of Clostridium, Bifidobacterium, and Lactobacillus genera (Supplementary Fig. 2). The remaining $30 \%$ of the microbiota s characterized by bacteria from other sources like the human perianal zone [38]. These results strongly suggest that colostrum is an essential source of neonate bacteria and its association with IgA2 regulates the microbiota establishment in the newborn intestine.

\section{The predicted microbial metabolic pathways among $\operatorname{lgA} 2+$ bacteria are enriched in intestinal colonization and active metabolism.}

Finally, a diversity analysis of the association of microbiota with predicted metabolic pathways was implemented by statistical tool PICRUSt) to analyze which metabolic pathways may be involved by the relative abundances of bacteria present in the samples and examine whether there are disparities in bacterial composition between IgA2 + fractions of colostrum and feces of neonates exclusively fed with breast milk. PICRUSt analysis identified nine functional metabolic pathways and showed that, despite their different inter-and intra-individual variation (alpha and beta diversity) in intestinal microbiota composition from neonates and colostrum, they have particular functional profiles. In general, lgA2 + bacteria in feces from breastfed infants showed a significantly increased abundance of metabolic pathways. These pathways were overrepresented in feces samples from infants fed with colostrum $(p<$ 0.04) compared to infants fed with formula. Among them, bacterial invasion of epithelial cells, folate biosynthesis, and carbohydrate metabolism had the most significant difference $(p=1.34 \mathrm{e}-4)$. In the same way, transcription machinery, fatty acid metabolism and pentose-glucoronate interconversions metabolic pathways were underrepresented in the same fractions (6.76e-3) (Fig. 5). All these data suggest that IgA2 association could help to shape microbiota on neonate during bacteria colonization, providing an advantage to associate specific genera enriched with folate biosynthesis and carbohydrate metabolism to establish in the mucosal intestine. 


\section{Bacteria association with $\operatorname{lgA} 2$ is dependent on glycans/protein recognition.}

Since our results indicated an enrichment of metabolic pathways associated with folate and carbohydrates synthesis, we decided to evaluate whether, as previously published [34,39], the IgA subclasses presented differential recognition on antigens depending on their chemical nature. Our data showed IgA2 affinity for carbohydrates like N-acetylglucosamine (D-GIcNAc), D-Mannose (D-Man), and alpha-D-Mannose (a-D-Map) which are expressed on the bacterial external membrane or wall cell (Fig. 6a). Both colostrum IgA subclasses recognize SHMT, present in both isolated fractions (IgA $1+$ and IgA2+) (Fig. 6b). These data suggest that the recognition of IgA by bacteria in colostrum is the product of a polyreactive effect to common antigens among different bacterial genera, similar to what occurs in the intestine [34].

\section{Discussion}

This work provides information about the role of colostrum IgA2 in microbiota colonization during the postnatal stage. We corroborated evidence that colostrum is one of the primary sources of bacteria, among other sources that colonizes the neonatal gastrointestinal tract from the first days of life.

According to previous studies [28, 40], we found that IgA subclasses show a differential recognition between bacteria groups in agreement with previous reports [26]. The predominance of IgA2 could be a consequence of IgA1 degradation by bacterial enzyme activity. Moreover, by lower microbiota density in colostrum, improving a more selective association with most immunogenic antigens on bacteria surface [41]. From these associations, our data suggest that bacteria decoration with colostrum IgA2 has more active participation during colostrum microbiota neonatal colonization.

We described that meconium microbiota was characterized by the Enterobacteriaceae family and Pseudomonas genera, with enrichment of Clostridium, Staphylococcus Streptococcus, which origin is still under discussion [42]. During vaginal birth, the neonate is colonized by maternal microbiota from the urogenital tract and perianal zone, characterized by Clostridium, Pseudomonas, Bifidobacterium, Lactobacillus, and Enterobacteriaceae. The mother provides colostrum feeding during the first three days, Lactobacillus, Bacteroides, Pseudomonas, Bifidobacterium, and Propionibacterium decorated with IgA2 $(\lg A 2+)$.

According to our results, breastfeeding cooperates to shape a neonatal intestinal microbiota increased in the Enterobacteriaceae family and Pseudomonas, Bacteroides, Bifidobacterium, Lactobacillus, and Propionibacterium; associated with IgA2 (IgA2+). Meanwhile, Paracoccus, Phyllobacteriaceae, and Clostridium remain without IgA association (IgA2-). This observation was corroborated when we compared our data with fecal samples from neonates fed with pasteurized milk. This milk had low content and diversity of microbiota, dominated by bacteria that can resist pasteurization processes like Clostridium and Pseudomonas [43]. This low-quality milk shapes an intestinal microbiota dominated mainly, by Clostridium, Pseudomonas, and Enterobacteriaceae, among others; associated with problems 
in neonate's health [44]. These results strongly suggest that colostrum provides and helps to modulate microbiota colonization.

We found that $\lg A 2$ decoration is driven, mainly, by glycans recognition on bacteria surfaces $[27,28,45$, 46]. Theoretically, this IgA has a medium/low affinity to recognize antigens. This association with $\lg A$ different bacterial communities may approach and bind to the mucus layer [47]. Association with IgA may promote a tolerogenic response against these bacteria [48, 49]. Finally, IgA may also generate niches with commensal bacteria communities in the intestine [50]. Thus, IgA may allow controlled colonization by non-pathogenic microbiota [51], improving their intestine establishment [52, 53].

On the other hand, Enterobacter, Propionibacterium, and Pseudomonas were bacterial genera that, only after three days of feeding with colostrum, were found to be associated with IgA2 in stool samples. These data suggest that IgA2 recognizes other bacterial genera already residing in the newborn gut. Through this interaction, soluble maternal $\lg \mathrm{A} 2$ could help to regulate the composition of the microbiota in situ.

Finally, some bacterial genera such as Paracoccus, Phyllobacteriaceae, and Clostridium, found in the newborn's intestine, were not associated with $\lg \mathrm{A} 2$. These data suggest that specific bacterial genera colonize independently of their association with maternal IgA2 or could be part of a temporal microbiota. Then, Paracoccus, Phyllobacteriaceae, and Clostridium could take advantage of the lgA2 + bacteria's metabolic activity previously established in the intestine for their late colonization. This result also suggests a much more dynamic interaction between the different bacterial genera that inhabits the intestine in the first moments of life [54]. However, more studies are needed to understand this phenomenon.

All these data suggest that IgA2 cooperates in shaping neonatal microbiota. These first transitory bacteria arriving at the intestine have some advantage over other bacteria settling late during colonization. Bacteria in the neonate's intestine produce metabolites that engineer conditions for mucosal immune system maturation and the next waves of microbiota establishing during the ablactation [55]. During the first round of colonization, the metabolites produced may regulate the subsequent settlement of bacteria in the following days of life. According to our data, the most widely represented metabolic pathways are folate synthesis and carbohydrate metabolism. Okay $S$ et al. determined that, in the mouse intestine, bacteria that expressed SHMT enzyme, which regulates folate metabolism, were recognized by high-affinity IgA. This interaction shapes microbiota composition in mice [34]; however, this issue is not well understood in humans.

In according with our results, bacteria IgA2 + at three days after breastfeeding, microbiota is represented by bacteria under early adaptation process. This step is overrepresented by carbohydrate consuming and bacterial invasion, among others, meanwhile, a slow growth ratio related by machinery transcription, fatty acid metabolism and pentose-glucoronate interconversions. Bifidobacterium, Lactobacillus and Propionibacterium genera represent metabolic pathways related with latency growth phase during the first three days of colonization [56]. These genera need to adapt at new intestinal conditions and consume carbohydrates to adapt and generate physicochemical conditions in small microbial niches 
[57]. After that, these bacteria must enter to logarithmic growth phase after five days of adaptation, increasing transcription and DNA and fatty acid synthesis.

This work's main limitation is that bacteria found in feces do not necessarily represent intestinal microbiota composition. Feces have become the reference of most bacteria studies because of is a noninvasive methodology, and sampling is easy and convenient. Previous studies in animal models had demonstrated an essential variation between samples [58]. Perhaps, fecal samples could be more similar to intestinal microbiota composition in neonates because before delivery is a relatively sterile mucosa [59]. However, more studies are necessary to clarify if feces analysis truly represents intestinal microbiota in the newborn. Of course, breastfeeding is only one of the many microbiota sources during the first days of life. According to our results, IgA2 plays an active role in the maternal microbiota's colonization process in the newborn's intestine. However, functional studies and animal models must verify that this association has biological relevance and a beneficial effect on the newborn's health. This work was focused on IgA2 role during bacteria colonization. Besides, IgA1 could have a more active activity in shaping neonate microbiota during defense against pathogens and stimulating other bacteria's colonization. Future studies in animal models are necessary due to the experimental limitation described above.

The present work contributes to the knowledge of human milk and neonatal stool microbiota in a healthy population and supports the idea of mother-neonate transmission through exclusive breastfeeding.

\section{Conclusion}

IgA2 shapes neonatal microbiota composition in the intestine by associating colostrum bacteria through glycans surface recognition to provide them an evolutionary advantage during colonization, at least three days. These genera describe metabolic profiles to induce and control the subsequent genera colonization, suggesting an active role of this IgA2-microbiota association beyond the first days of life.

\section{Abbreviations}

List

$\lg \mathrm{A} 2$

immunoglobulin A subclass 2; IgA1:immunoglobulin A subclass 1; VD:vaginal delivery; ISSSTE:Instituto de Seguridad y Servicios Sociales de los Trabajadores del Estado; LEfSe:Linear discriminate $t$ analysis effect size; LDA:linear discrimination analysis; IgA-Seq:characterization of IgA-associated microbiota using flow cytometry coupled with $16 \mathrm{~S}$ rDNA gene sequencing

Author details

${ }^{1}$ Departamento de Biomedicina Molecular, Centro de Investigación y de Estudios Avanzados del IPN del Instituto Politécnico Nacional (CINVESTAV-IPN). Mexico City, Mexico.

${ }^{2}$ Hospital Regional $1^{\circ}$ de Octubre, Instituto de Seguridad y Servicios Sociales de los Trabajadores del Estado (ISSSTE), Departamento de Ginecología. Mexico City, Mexico. 
${ }^{3}$ Departamento de Genética y Biología Molecular, Centro de Investigación y de Estudios Avanzados del IPN del Instituto Politécnico Nacional (CINVESTAV-IPN). Mexico City, Mexico.

Author's information

E Sánchez-Salguero

erick.sanchez@cinvestav.mx, H Guzmán-Aquino:hectorguzman.wow@gmail.com, MF de la Borbolla-

Cruz:fergybella_12@hotmail.com, V Contreras-Vargas:vicman2yk@hotmail.com, K Corona-

Cervantes:karina.corona@cinvestav.mx, A Piña-Escobedo:apinae@cinvestav.mx and J García-

Mena:jgmena@cinvestav.mx

\section{Declarations}

\section{Acknowledgments}

The authors would like to thank the mother-child binomial, who participated in this study. We would like to thank M.Scs. Loan Edel Villalobos-Flores and Fernando Hernández-Quiroz who provide technical help

to develop molecular biology techniques and bioinformatics analysis. We thank Dr. Reiko Shinkura for the W27 antibody donation that helped us develop some of the experiments performed in this work.

\section{Funding}

This research was supported by grants from Consejo Nacional de Ciencia y Tecnología (CONACYT), Mexico (PDCPN 2015/900) to LSA, CONACyT 163235 INFR-2011-01 granted to JGM, and SEP-Cinvestav funding (174) to LSA and JGM. ESS received a scholarship (706312) from CONACYT.

\section{Availability of data and material}

Datasets used during this study can be obtained from the corresponding author on request. The sequence and corresponding mapping files for all samples used in this study were deposited in the NCBI BioSample repository (accession number: PRJNA707069)

https://www.ncbi.nlm.nih.gov/sra/PRJNA707069

\section{Author's contributions}

ESS performed experiments, analyzed the data, interpreted the results, and wrote the manuscript. HGA and MFBC contributed to the acquisition of samples, collected clinical information, and participate in flow cytometry assays. KCC participated in molecular biology experiments. VMCV supervised the sampling process, provided clinical information, and registered the protocol at the hospital. APE was responsible for the massive sequencing process. JGM and LSA conceived and designed the study, wrote, and revised the manuscript's final version. All authors read and approved the final version.

\section{Ethics approval}


The Research and Ethics Reviewing Board approved the study protocol of Protocols from HR $1^{\circ}$ Oct (with number 090201/14.1/086/2017).

\section{Consent for publication}

Not applicable

\section{Competing interests}

The authors reported no potential conflict of interest.

\section{References}

1. Selma-Royo M, Tarrazó M, García-Mantrana I, Gómez-Gallego C, Salminen S, Collado M. Shaping Microbiota during the first 1000 days of life. Adv Exp Med Biol-Advances in Microbiology, Infectious Diseases, and Public Health. 2018. https://doi.org/10.1007/5584_2018_312.

2. Korpela K, Helve O, Kolho KL, Saito T, Skogberg K, Dikareva E, Stefanovic V, Salonen A, Andersson S, de Vos WM. Maternal Fecal Microbiota Transplantation in Cesarean-Born Infants Rapidly Restores Normal Gut Microbial Development: A Proof-of-Concept Study. Cell. 2020 Oct 15;183(2):324-334.e5. DOI: 10.1016/j.cell.2020.08.047. Epub 2020 Oct 1. PMID: 33007265.

3. Urbaniak C, Cummins J, Brackstone $M$, et al. microbiota of human breast tissue. Appl Environ Microbiol. 2014;80(10):3007-14. DOI:10.1128/AEM.00242-14.

4. Moosavi S, et al. Composition and variation of the human milk microbiota are influenced by maternal and early-life factors. Cell Host Microbe. 2019;25:324-35.

5. Gomez de Agüero M, Ganal-Vonarburg SC, Fuhrer T, Rupp S, Uchimura Y, Li H, Steinert A, Heikenwalder M, Hapfelmeier S, Sauer U, McCoy KD, Macpherson AJ. The maternal microbiota drives early postnatal innate immune development. Science. 2016 Mar 18; 351(6279):1296 - 302. Doi: 10.1126/science.aad2571. PMID: 26989247.

6. Wan Y, Jiang J, Lu M, Tong W, Zhou R, Li J, Yuan J, Wang F, Duo Li. Human milk microbiota development during lactation and its relation to maternal geographic location and gestational hypertensive status. Gut Microbes. 2020;11(5):1438-49. DOI:10.1080/19490976.2020.1760711.

7. Corona-Cervantes K, García-González I, Villalobos-Flores LE, Hernández-Quiroz F, Piña-Escobedo A, Hoyo-Vadillo C, Rangel-Calvillo MN, García-Mena J. Human milk microbiota associated with early colonization of the neonatal gut in Mexican newborns. PeerJ. 2020;8:e9205. http://doi.org/10.7717/peerj.9205.

8. Demmelmair H, Esther Jiménez MC, Collado S, Salminen, Michelle K, McGuire. Maternal and Perinatal Factors Associated with the Human Milk Microbiome, Current Developments in Nutrition, Volume 4, Issue 4, April 2020, nzaa027, https://doi.org/10.1093/cdn/nzaa027.

9. Fehr K, Moussavi S, Sbihi H, Boutin RCT, Bode L, Robertson B, Yonemitsu C, Field CJ, Becker AB, Mandhane PJ, Sears MR, Khafipour E, Moraes TJ, Subbarao P, Finlay BB, Turvey SE, Azad MB. 
Breastmilk Feeding Practices Are Associated with the Co-Occurrence of Bacteria in Mothers' Milk and the Infant Gut: the CHILD Cohort Study. Cell Host Microbe. 2020 Aug 12;28(2):285-297.e4. DOI: 10.1016/j.chom.2020.06.009. Epub 2020 Jul 10. PMID: 32652062.

10. Knoop K, Gustafsson J, McDonald K, et al. Microbial antigen encounter during a preweaning interval is critical for tolerance to gut bacteria. 2017. Science Immunology. 2(18): eaao1314.

10.1126/sciimmunol.aao1314.

11. Korpela K, de Vos WM. Early life colonization of the human gut: microbes matter everywhere. Curr Opin Microbiol. 2018 Aug;44:70-8. DOI:10.1016/j.mib.2018.06.003. Epub 2018 Aug 4. PMID: 30086431.

12. Tanaka M, Nakayama J. Development of the gut microbiota in infancy and its impact on health in later life. Allergol Int. 2017 Oct;66(4):515-22. Doi:10.1016/j.alit.2017.07.010. Epub 2017 Aug 18. PMID: 28826938.

13. Kulkarni DH, Gustafsson J, Davis J, McDonald K, Hsieh C, Rodney D, Newberry. Intestinal Goblet cells and Goblet Cell Associated Antigen Passages regulate the balance between Tregs and Th17. The Journal of Immunology May 1, 2019, 202 (1 Supplement) 129.17.

14. Knoop KA, Coughlin PE, Floyd AN, Ndao IM, Hall-Moore C, Shaikh N, Gasparrini AJ, Rusconi B, Escobedo M, Good M, Warner BB, Tarr PI, Newberry RD. Maternal activation of the EGFR prevents translocation of gut-residing pathogenic Escherichia coli in a model of late-onset neonatal sepsis. Proc Natl.

15. Brandtzaeg P. The mucosal immune system and its integration with the mammary glands. J Pediatr. 2010;156(Suppl2):8-15. DOI:10.1016/j.peds.2009.11.014.

16. Palm NW, de Zoete MR, Cullen TW, Barry NA, Stefanowski J, Hao L, Degnan PH, Hu J, Peter I, Zhang W, Ruggiero E, Cho JH, Goodman AL, Flavell RA. Immunoglobulin A coating identifies colitogenic bacteria in inflammatory bowel disease. Cell. 2014 Aug 28; 158(5):1000-1010. DOI: 10.1016/j.cell.2014.08.006. PMID: 25171403; PMCID: PMC4174347.

17. Demers-Mathieu V, Underwood M, Beverly R, Nielsen S, Dallas D. Comparison of human milk immunoglobulin survival during gastric digestion between preterm and term infants. Nutrients. 2018;10:631. doi:10.3390/nu10050631.

18. Pabst O, Cerovic V, Hornef M. Secretory IgA in the Coordination of Establishment and Maintenance of the Microbiota. Trends Immunol. 2016 May;37(5):287-96. DOI:10.1016/j.it.2016.03.002. Epub 2016 Apr 5. PMID: 27066758.

19. Fadlallah J, El Kafsi H, Sterlin D, Juste C, Parizot C, Dorgham K, Autaa G, Gouas D, Almeida M, Lepage P, Pons N, Le Chatelier E, Leverenz F, Kennedy S, Galleron N, de Barros JP, Malphettes M, Glacier L, Boutboul D, Mathian A, Miyara M, Oksenhendler E, Amoura Z, Doré J, Fieschi C, Ehrlich SD, Larsen M, Gorochov G. Microbial ecology perturbation in human IgA deficiency. Sci Transl Med. 2018 May 2; 10(439):eaan1217. Doi: 10.1126/scitransImed.aan1217. PMID: 29720448.

20. Macpherson AJ, Yilmaz B. Antibodies that IlgAte our intestinal microbes. Sci Immunol. 2018; 3eaat4037. doi:10.1126/sciimmunol.aat4037. 
21. González R, Maldonado A, Martín V, Mandomando I, Fumadó V, Metzner KJ, Sacoor C, Fernández L, Macete $\mathrm{E}$, Alonso PL, Rodríguez JM, Menendez C. Breast milk and gut microbiota in African mothers and infants from an area of high HIV prevalence. PLoS One. 2013 Nov 26; 8(11):e80299. Doi: 10.1371/journal.pone.0080299. Erratum in: PLoS One. 2014; 9(3):e92930. PMID: 24303004; PMCID: PMC3841168.

22. Bunker JJ, Bendelac A. IgA Responses to Microbiota. Immunity. 2018 Aug;21(2):211-24. Doi:10.1016/j.immuni.2018.08.011. PMID: 30134201; PMCID: PMC6107312. 49) .

23. Bunker JJ, Flynn TM, Koval JC, Shaw DG, Meisel M, McDonald BD, Ishizuka IE, Dent AL, Wilson PC, Jabri B, Antonopoulos DA, Bendelac A. Innate and Adaptive Humoral Responses Coat Distinct Commensal Bacteria with Immunoglobulin A. Immunity. 2015 Sep 15; 43(3):541-53. DOI: 10.1016/j.immuni.2015.08.007. Epub 2015 Aug 25. PMID: 26320660; PMCID: PMC4575282.

24. Pabst O, Slack E. IgA, and the intestinal Microbiota: the importance of being specific. Mucosal Immunol. 2020;13:12-21. https://doi.org/10.1038/s41385-019-0227-4.

25. De Sousa-Pereira P, Woof JM. IgA. Structure, Function, and Develop ability. Antibodies (Basel). 2019;8(4):57. doi:10.3390/antib8040057. Published 2019 Dec 5.

26. Sterlin D, Fadlallah J, Adams O, Fieschi C, Parizot C, Dorgham K, Rajkumar A, Autaa G, El-Kafsi H, Charuel JL, Juste C, Jönsson F, Candela T, Wardemann H, Aubry A, Capito C, Brisson H, Tresallet C, Cummings RD, Larsen M, Yssel H, von Gunten S, Gorochov G. Human IgA binds a diverse array of commensal bacteria. J Exp Med. 2020 Mar 2; 217(3):e20181635. DOI: 10.1084/jem.20181635. Erratum in: J Exp Med. 2020 Mar 2; 217(3): PMID: 31891367; PMCID: PMC7062531.

27. Ladjeva I, Peterman JH, Mestecky J. IgA subclasses of human colostral antibodies specific for microbial and food antigens. Clin Exp Immunol. 1989;78(1):85-90.

28. Sánchez-Salguero ES, Rodríguez-Chacón BC, Leyva-Daniel J, Zambrano-Carrasco J, MiguelRodríguez CE, Santos-Argumedo L. Antigenic stimulation during pregnancy modifies specific IgA1 and IgA2 subclasses in human colostrum according to the chemical composition of the antigen. Rev Invest Clin. 2020; 72(2):80-87. Doi: 10.24875/RIC.19003230. PMID: 32284627.

29. Appleton J, Laws R, Russell CG, Fowler C, Campbell KJ, Denney-Wilson E. Infant formula feeding practices and the role of advice and support: an exploratory qualitative study. BMC Pediatr. 2018; 18(1):12. Published 2018 Jan 24. doi:10.1186/s12887-017-0977-7.

30. Sánchez-Salguero E, Mondragón-Ramírez GK, Alcántara-Montiel JC, et al. Infectious episodes during pregnancy, at particular mucosal sites, increase specific IgA1 or IgA2 subclass levels in human colostrum. Matern health neonatol perinatol. 2019;5:9. https://doi.org/10.1186/s40748-019-0104-x.

31. Maya-Lucas O, Murugesan S, Nirmalkar K, Alcaraz LD, Hoyo-Vadillo C, Pizano-Zárate ML, GarcíaMena J. The gut microbiome of Mexican children affected by obesity. Anaerobe. 2019 Feb; 55:1123. Doi: 10.1016/j.anaerobe.2018.10.009. Epub 2018 Oct 24. PMID: 30366118.

32. Caporaso JG, Kuczynski J, Stombaugh J, Bittinger K, Bushman FD, Costello EK, Fierer N, Peña AG, Goodrich JK, Gordon JI, Gordon JL, Huttley GA, Kelley ST, Knights D, Koenig JE, Ley RE, Lozupone CA, McDonald D, Muegge BD, Pirrung M, Reeder J, Sevinsky JR, Turnbaugh PJ, Walters WA, Widmann J, 
Yatsunenko T, Zaneveld J, Knight R. QIIME allows analysis of high-throughput community sequencing data. Nat Methods. 2010;7:335-6. DOI 10.1038/nmeth.f.303.

33. Knights D, Kuczynski J, Charlson ES, Zaneveld J, Mozer MC, Collman RG, Bushman FD, Knight R, Kelley ST. Bayesian community-wide culture-independent microbial source tracking. Nat Methods. 2011;8:761763. DOI 10.1038/nmeth. 1650.

34. Okai S, Usui F, Ohta M, et al. Intestinal IgA as a modulator of the gut microbiota. Gut Microbes. 2017;8(5):486-92. DOI:10.1080/19490976.2017.1310357.

35. Young SL, Mbuya MN, Chantry CJ, Geubbels EP, Israel-Ballard K, Cohan D, Vosti SA, Latham MC. Current knowledge and future research on infant feeding in the context of HIV: basic, clinical, behavioral, and programmatic perspectives. Adv Nutr. 2011 May;2(3):225-43.

Doi:10.3945/an.110.000224. Epub 2011 Apr 30. PMID: 22332055; PMCID: PMC3090166.

36. Bodé S, Dreyer M, Greisen G. Gastric emptying, and small intestinal transit time in preterm infants: a scintigraphic method. J Pediatr Gastroenterol Nutr. 2004 Oct; 39(4):378 - 82. Doi:

10.1097/00005176-200410000-00014. PMID: 15448428.

37. Woof J, Russell M. Structure, and function relationships in IgA. Mucosal immunology. 2017;4(6):590-7. DOI:10.1038/mi.2011.39.

38. Williams JE, Carrothers JM, Lackey KA, Beatty NF, Brooker SL, Peterson HK, Steinkamp KM, York MA, Shafii B, Price WJ, McGuire MA, McGuire MK. Strong Multivariate Relations Exist Among Milk, Oral, and Fecal Microbiomes in Mother-Infant Dyads During the First Six Months Postpartum. J Nutr. 2019 Jun 1;149(6):902-914. DOI: 10.1093/jn/nxy299. PMID: 31063198; PMCID: PMC6543206.

39. Huus KE, Bauer KC, Brown EM, Bozorgmehr T, Woodward SE, Serapio-Palacios A, Boutin RCT, Petersen C, Finlay BB. Commensal Bacteria Modulate Immunoglobulin A Binding in Response to Host Nutrition. Cell Host Microbe. 2020 Jun 10; 27(6):909-921.e5. DOI:

10.1016/j.chom.2020.03.012. Epub 2020 Apr 13. PMID: 32289261.

40. Stellwagen K, Carpenter E, Haigh B, Hodgkinson A, Wheeler TT. Immune components of bovine colostrum and milk. J Anim Sci. 2009 Apr;87(13 Suppl):3-9. DOI:10.2527/jas.2008-1377. Epub 2008 Oct 24. PMID: 18952725.

41. Bunker JJ, Bendelac A. IgA Responses to Microbiota. Immunity. 2018 Aug;21(2):211-24. Doi:10.1016/j.immuni.2018.08.011. PMID: 30134201; PMCID: PMC6107312. 49 ) .

42. He Q, Kwok LY, Xi X, Zhong Z, Ma T, Xu H, Meng H, Zhao F, Zhang H. The meconium microbiota shares more features with the amniotic fluid microbiota than the maternal fecal and vaginal microbiota. Gut Microbes. 2020 Nov 9;12(1):1794266. DOI: 10.1080/19490976.2020.1794266. PMID: 32744162; PMCID: PMC7524391.

43. Maier $C$, Hofmann $K$, Huptas $C$, et al. Simultaneous quantification of the most common and proteolytic Pseudomonas species in raw milk by multiplex qPCR. Appl Microbiol Biotechnol. 2021;105:1693-708. https://doi.org/10.1007/s00253-021-11109-0.

44. Laube R, Paramsothy S, Leong RP. Use of medications during pregnancy and breastfeeding for Crohn's disease and ulcerative colitis, Expert Opinion on Drug Safety. (2021) DOI: 
10.1080/14740338.2021.1873948.

45. Kunkel EJ, Butcher EC. Plasma-cell homing. Nat Rev Immunol. 2003 Oct; 3(10):822-9. Doi: 10.1038/nri1203. PMID: 14523388.

46. Patel P, Kearney J. Immunological outcomes of antibody binding to glycans shared between microorganisms and mammals. J Immunol. 2016;197:(11)4201-9. doi.org/10.4049/jimmunol.1600872.

47. Rogier EW, Frantz AL, Bruno ME, Kaetzel CS. Secretory IgA is Concentrated in the Outer Layer of Colonic Mucus along with Gut Bacteria. Pathogens. 2014 Apr 29;3(2):390-403. DOI: 10.3390/pathogens3020390. PMID: 25437806; PMCID: PMC4243452.

48. Brandtzaeg P. Secretory IgA: designed for antimicrobial defense. Front Immunol 2013 6; 4: 222. Doi: 10.3389/fimmu.2013.00222. eCollection 2013.

49. Al Nabhani Z, Dulauroy S, Marques R, Cousu C, Al Bunny S, Déjardin F, Sparwasser T, Bérard M, CerfBensussan N, Eberl G. A Weaning Reaction to Microbiota Is Required for Resistance to Immunopathologies in the Adult. Immunity. 2019 May 21; 50(5):1276-1288.e5. Doi: 10.1016/j.immuni.2019.02.014. Epub 2019 Mar 19. PMID: 30902637.

50. Bergstrom K, Shan X, Casero D, Batushansky A, Lagishetty V, Jacobs JP, Hoover C, Kondo Y, Shao B, Gao L, Zandberg W, Noyovitz B, McDaniel JM, Gibson DL, Pakpour S, Kazemian N, McGee S, Houchen CW, Rao CV, Griffin TM, Sonnenburg JL, McEver RP, Braun J, Xia L. Proximal colon-derived O-glycosylated mucus encapsulates and modulates the microbiota. Science. 2020 Oct 23;370(6515):467-472. DOI: 10.1126/science.aay7367. PMID: 33093110.

51. Fransen F, Zagato E, Mazzini E, Fosso B, Manzari C, El Aidy S, Chiavelli A, D'Erchia AM, Sethi MK, Pabst O, Marzano M, Moretti S, Romani L, Penna G, Pesole G, Rescigno M. BALB/c and C57BL/6 Mice Differ in Polyreactive IgA Abundance, which Impacts the Generation of Antigen-Specific IgA and Microbiota Diversity. Immunity. 2015 Sep 15;43(3):527 - 40. doi: 10.1016/j.immuni.2015.08.011. Epub 2015 Sep 8. PMID: 26362264.

52. Moor K, Diard M, Sellin M, et al. High-avidity IgA protects the intestine by enchaining growing bacteria. Nature. 2017;544:498-502. https://doi.org/10.1038/nature22058.

53. Dimitrov JD, Lacroix-Desmazes S. Noncanonical Functions of Antibodies. Trends Immunol. 2020 May;41(5):379-393. DOI: 10.1016/j.it.2020.03.006. Epub 2020 Apr 6. PMID: 32273170.

54. Huus KE, Petersen C, Finlay BB. Diversity and dynamism of IgA-microbiota interactions. Nat Rev Immunol. 2021 Feb 10. DOI: 10.1038/s41577-021-00506-1. Epub ahead of print. PMID: 33568782.

55. Gopalakrishna KP, Hand TW. Influence of Maternal Milk on the Neonatal Intestinal Microbiome. Nutrients. 2020 Mar 20;12(3):823. DOI: 10.3390/nu12030823. PMID: 32244880; PMCID: PMC7146310.

56. Parkar SG, Kalsbeek A, Cheeseman JF. Potential Role for the Gut Microbiota in Modulating Host Circadian Rhythms and Metabolic Health. Microorganisms. 2019 Jan 31;7(2):41. doi: 10.3390/microorganisms7020041. PMID: 30709031; PMCID: PMC6406615. 
57. Pokhrel B, Koirala T, Shah G, Joshi S, Baral P. Bacteriological profile and antibiotic susceptibility of neonatal sepsis in neonatal intensive care unit of a tertiary hospital in Nepal. BMC Pediatr. 2018;18(1):208. Published 2018 Jun 27. doi:10.1186/s12887-018-1176-x.

58. Tang Q, Jin G, Wang G, et al. Current Sampling Methods for Gut Microbiota: A Call for More Precise Devices. Front Cell Infect Microbiol. 2020;10:151. doi:10.3389/fcimb.2020.00151. Published 2020 Apr 9.

59. Stinson Lisa F, Boyce Mary C, Payne Matthew S, Keelan Jeffrey A. The Not-so-Sterile Womb: Evidence That the Human Fetus Is Exposed to Bacteria Prior to Birth. Frontiers in Microbiology (10) 20191124

https://www.frontiersin.org/article/10.3389/fmicb.2019.0112410.3389/fmicb.2019.01124.

\section{Figures}
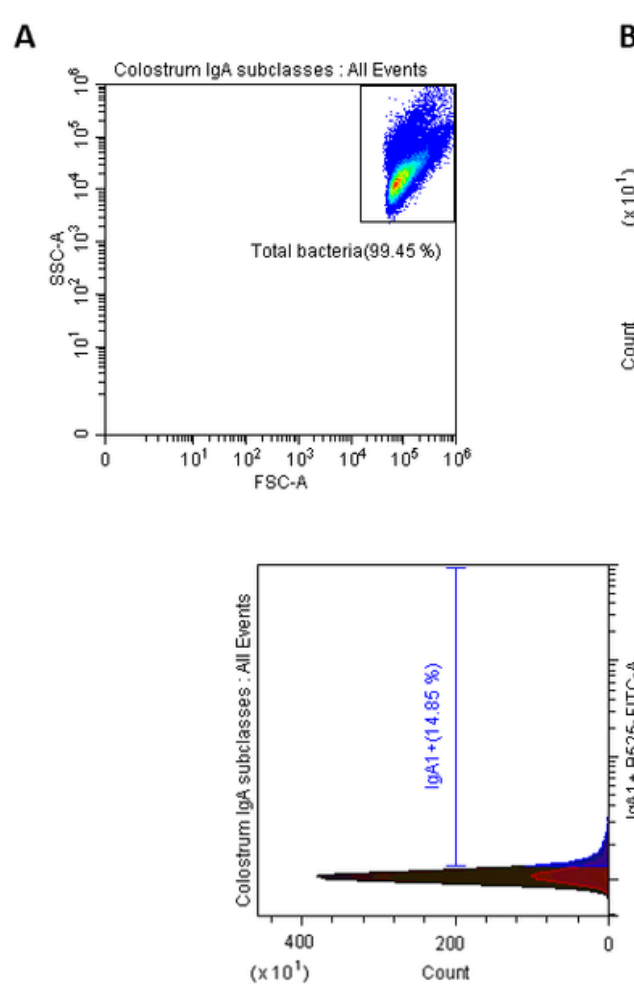

B
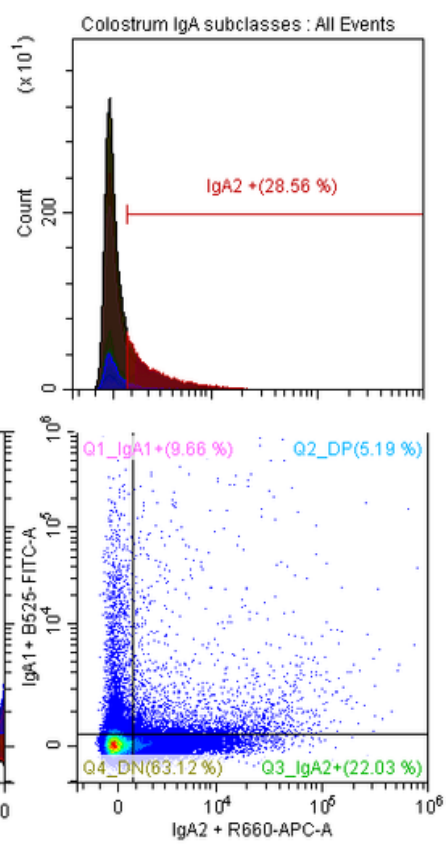

C

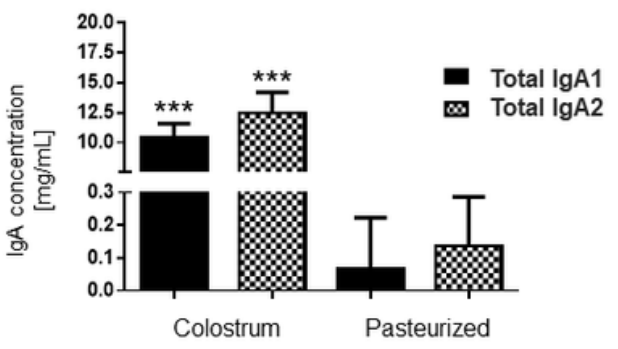

D

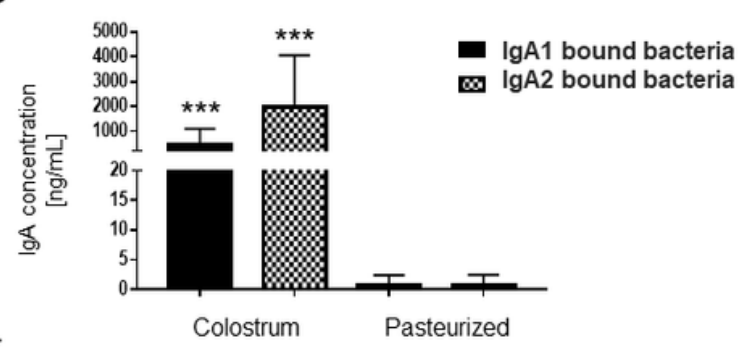

$\mathrm{E}$

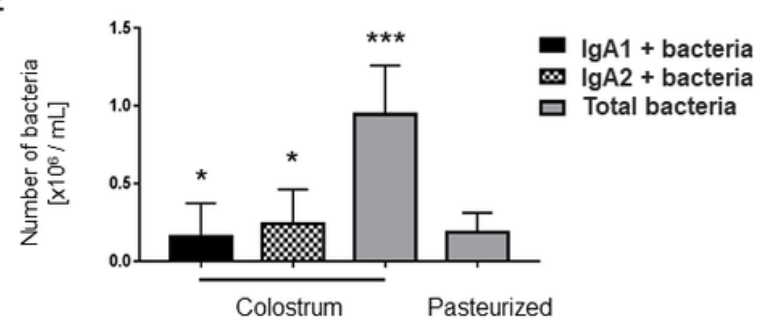

\section{Figure 1}

Microbiota from the human colostrum is differentially decorated with IgA subclasses. A) Staining profiles of bacteria in human colostrum characterized by flow cytometry. B) Analysis of bacterial populations by their associations with IgA1 (APC Cy7) and IgA2 (FITC) in human colostrum. C) Quantification of IgA subclasses in colostrum, titled "Colostrum" ( $n=96)$, and pasteurized milk, titled "Pasteurized" $(n=8)$ : by ELISA. Data are expressed in milligrams of IgA subclasses per milliliter of the sample $(\mathrm{mg} / \mathrm{mL})$. D) Semiquantification by Western blot of IgA subclasses' levels bound to bacteria, data are expressed in 
nanograms of $\lg A$ subclasses per milliliter of the sample $(\mathrm{ng} / \mathrm{mL})$. IgA1 (black bars) and IgA2 levels (filled bars). E) Numbers of bacteria determined by flow cytometry. Data are expressed in millions of bacteria per milliliter of the sample (106 bacteria/mL). IgA1+ (black bars), IgA2+ (filled bars) and total bacteria (gray bars). All values are represented as mean \pm standard deviation (SD). Statistical analysis was performed using the $U$ Mann-Whitney test, comparing each IgA subclasses level with the pasteurized milk sample as a control. ${ }^{*} \mathrm{p}<0.05$ and ${ }^{* \star *} \mathrm{p}<0.001$.

A

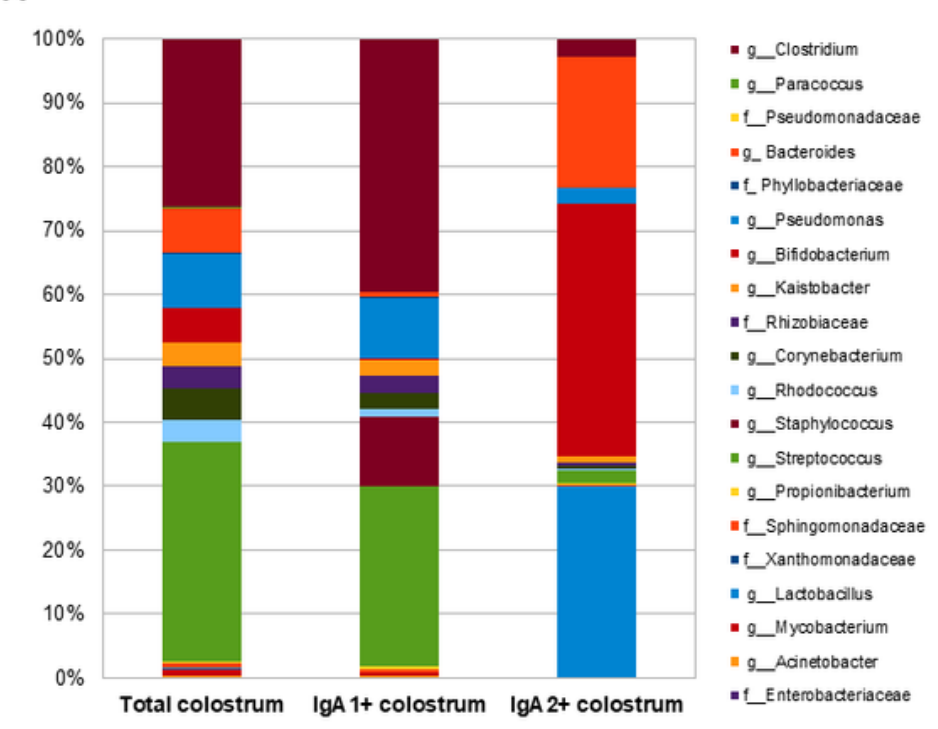

B

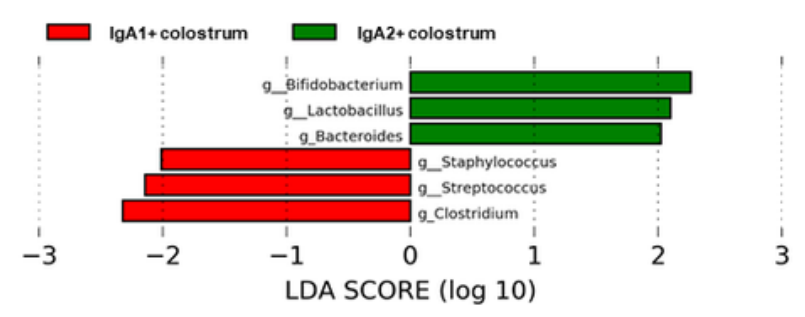

C

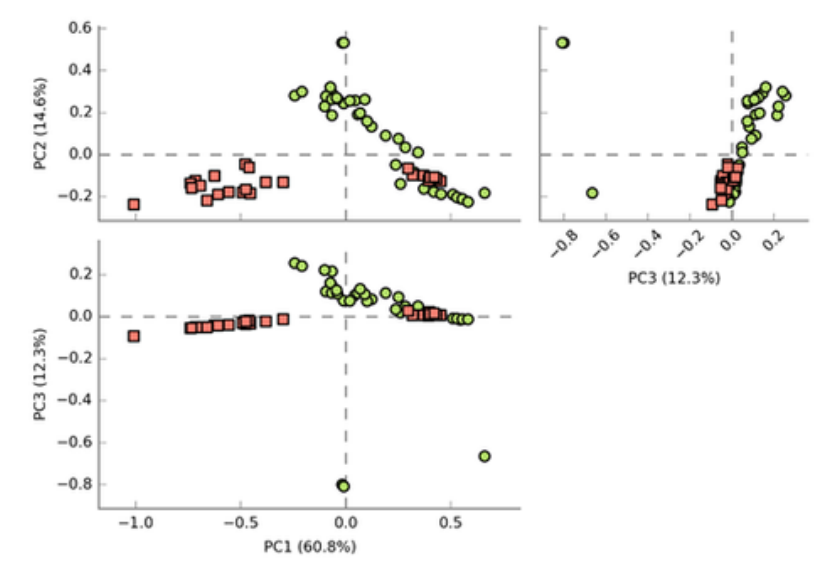

Figure 2 
Some bacteria have divergent recognition between IgA subclasses in the human colostrum. A) Relative abundance of predominant bacterial taxa in colostrum samples. Abundance of each families/genera in $\lg A$ fractions (Total bacteria in colostrum $=$ Total colostrum, bacteria associated with $\lg A 1=\lg A 1+$ colostrum, and bacteria associated with $\lg A 2=\operatorname{lgA} 2+$ colostrum). B) LEfSe analysis of the most representative bacterial genera in colostrum by $\lg A 1$ and IgA2. Linear discriminant analysis (LDA) effect size (LEfSe) comparison of differential abundant bacterial taxa between IgA fractions. Horizontal bars represent each taxon's effect size: green color indicates taxa enriched in IgA2+ fraction group, and red color indicates taxa enriched IgA1+ fraction group. LDA score cutoff of 2.0 was used to discriminate bacterial taxon. Total bacteria $(n=30), \lg A 1+(n=30)$ and $\lg A 2+$ bacteria fractions $(n=36)$. C) Beta diversity analysis. Two-dimensional scatterplots were generated using PCoA based on the unweighted UniFrac distance metric. PC3vsPC2, PC1vsPC2, and PC1vsPC3. Both groups significantly differed according to the ANOSIM similarity test $(R=0.289, p=0.001)$ and Adonis statistical test $(R 2=0.949, p=$ $0.001)$. $\lg A 1+$ fraction is plotted as red dots and $\lg A 2+$ fraction as green dots. $\lg A 1+(n=30)$ and $\lg A 2+$ bacteria fractions $(n=36)$.

A

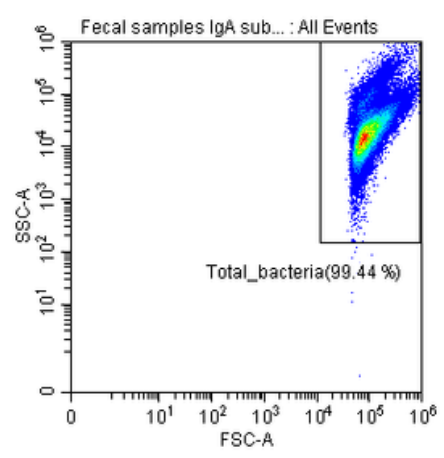

B

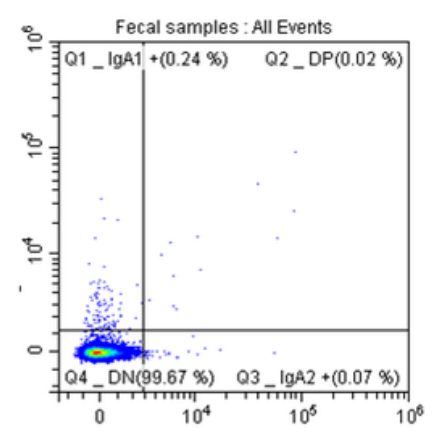

C
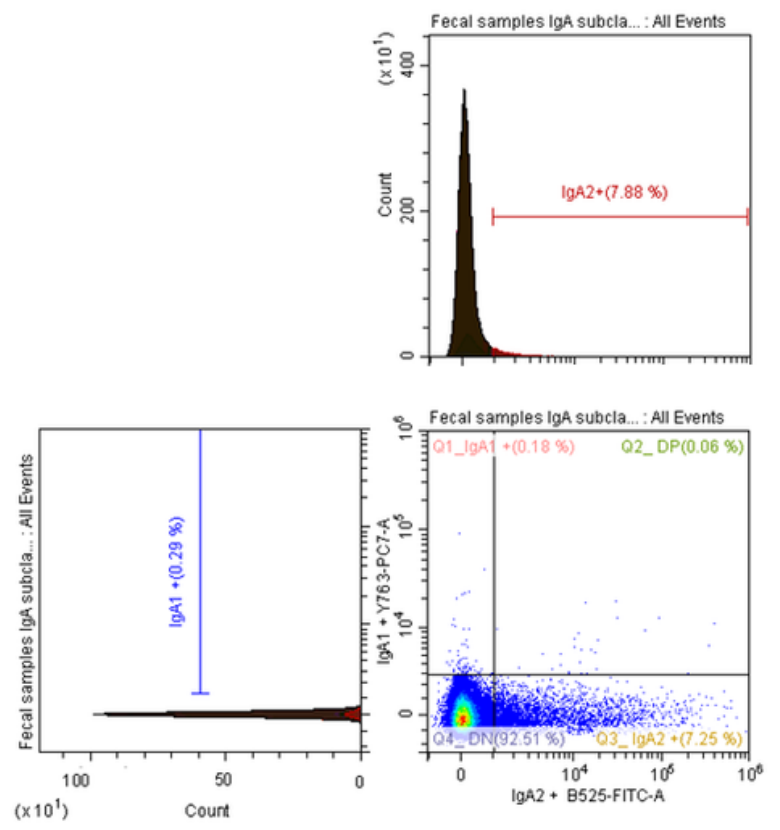

D

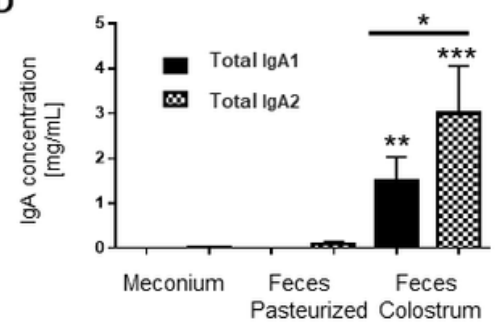

E

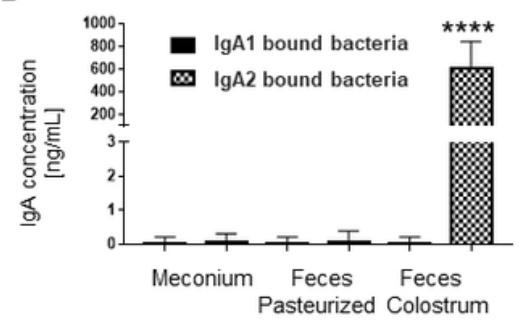

$\mathbf{F}$

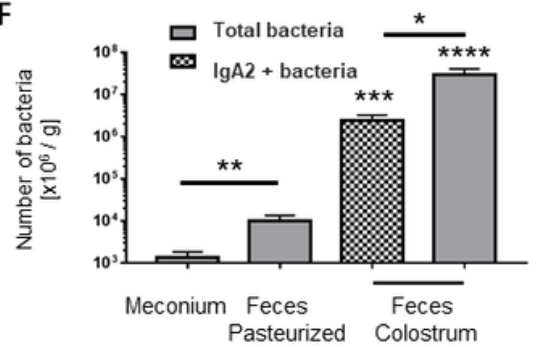

Figure 3

IgA2 is predominantly found coating bacteria in newborn feces of breastfed children. A) Dot blot of total bacteria in neonate's fecal samples. B) Bacteria found in meconium characterized by flow cytometry. C) Bacterial populations associated with IgA subclasses in stool samples after three days of colostrum-fed newborn children. D) Quantification by ELISA of IgA subclasses in meconium $(n=24)$, a stool sample from children fed with pasteurized milk, titled "Feces Pasteurized" $(n=8)$, or children fed with maternal colostrum, titled "Feces Colostrum" ( $n=25)$; data are expressed in milligrams of IgA per gram of fecal 
sample (mg/g). E) Semi-quantification by Western blot of IgA subclasses' levels bound to bacteria; data are expressed in nanograms of IgA per gram of fecal sample (ng/g). IgA1 (black bars) and IgA2 levels (filled bars). F) Number of bacteria determined by flow cytometry; data are expressed in millions of bacteria per gram of fecal sample (106 bacteria/g). IgA1+ (black bars), IgA2+ (filled bars) and total bacteria (gray bars). All values are represented as mean \pm standard deviation (SD). Statistical analysis was performed using the $U$ Mann-Whitney test between IgA subclasses in the same sample and comparing each level with meconium levels as control. ${ }^{\star} p<0.05,{ }^{*} \mathrm{p}<0.01,{ }^{\star \star \star} \mathrm{p}<0.001$ and ${ }^{\star \star \star \star} \mathrm{p}$ $<0.0001$.

A

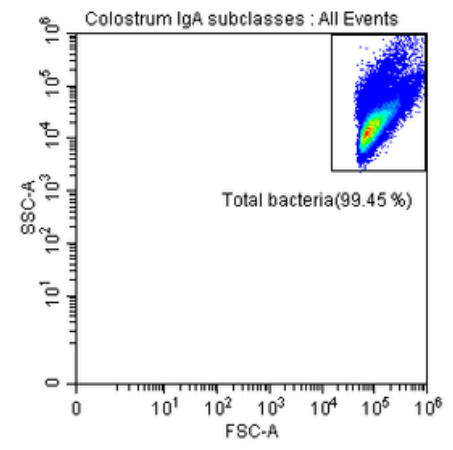

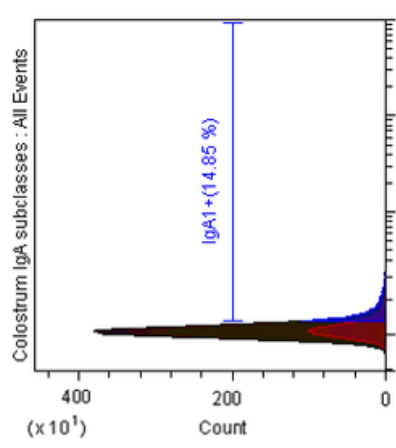

B
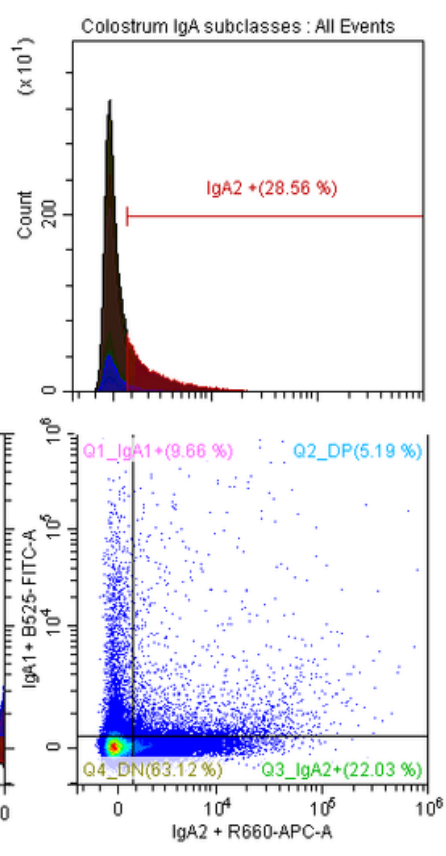

C

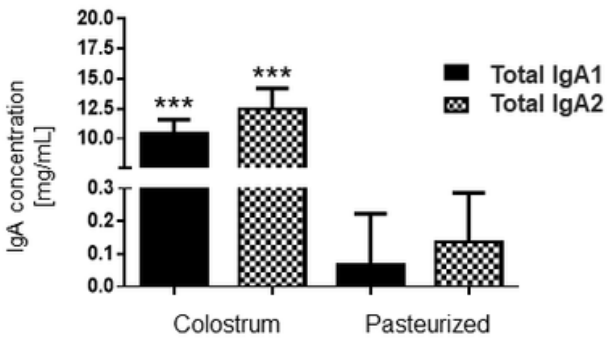

D

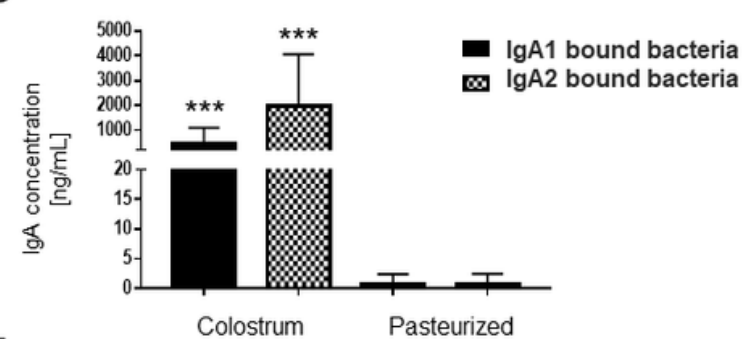

E

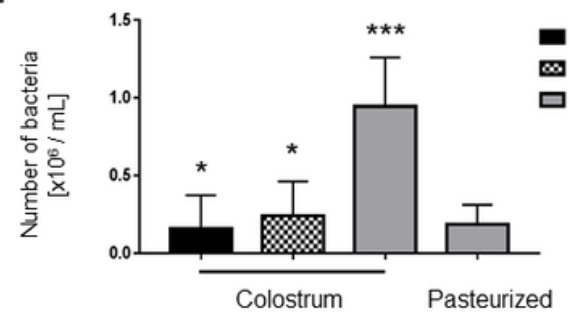

\section{Figure 4}

$\lg$ A2+ microbiota participate in the colonization of neonate's intestine. A) Relative abundance of predominant bacterial taxa in stool samples (Meconium, neonates fed with pasteurized milk= "Pasteurized," neonates fed with pasteurized milk= "Feces Pasteurized" and neonates fed with colostrum= "Feces Colostrum"; during first three days of life). The abundance of each family/genera in IgA fractions was compared between groups using parametric test for paired samples followed by BH correction. B) Determination of the alpha diversity indexes between feces samples: B) Alpha diversity based in observed number of species $(p<0.001)$, Chao1 $(p<0.001)$, Shannon $(p<0.001)$ and Simpson $(p=0.006)$ indexes. Mann-Whitney U-test was used to find significant differences. (Total $(n=30), \operatorname{lgA} 1+$ Colostrum $(n=30), \lg A 2+$ Colostrum $(n=36)$, Meconium $(n=24)$, Pasteurized milk $(n=8)$, Feces Pasteurized $(n=8)$, Feces Colostrum $(n=25)$ and IgA2+ bacteria fraction from feces of neonates fed with colostrum (Feces Colostrum IgA2+) $(n=30)$. Alpha diversity based on observed number species $(p<0.001)$, Chao1 $(p<$ 0.001), Shannon ( $p<0.001)$ and Simpson $(p<0.005)$ indexes. Mann-Whitney U-test was used to find 
significant differences. C) LEfSe analysis of the most representative bacterial genera in stool samples. Linear discriminant analysis (LDA) effect size (LEfSe) comparison of differentially abundant bacterial taxa among free fecal bacteria ("Feces Colostrum IgA-") and IgA2+ fecal bacteria ("Feces Colostrum IgA2+"); from neonates whose were fed with colostrum during the first three days of life. Horizontal bars represent each taxon's effect size: green color indicates taxa enriched in IgA2+ fraction group, and red color indicates free taxa enriched group. LDA score cutoff of 3.4 was used to discriminate bacterial taxon. D) Beta diversity analysis. Two-dimensional scatterplots were generated using PCoA based on the unweighted UniFrac distance metric. PC3vsPC2, PC1vsPC2, and PC1vsPC3. Both groups significantly differed according to the ANOSIM similarity test $(R=0.289, p=0.001)$ and Adonis statistical test $(R 2=$ $0.949, p=0.001)$. Total bacteria from colostrum sample in red $(n=36)$, IgA2+ fecal bacteria from neonates fed with colostrum in green $(n=30)$, total fecal bacteria from neonates fed with colostrum in yellow $(n=15)$, total bacteria from meconium in blue $(n=22)$ and total bacteria from pasteurized milk $(n=$ $5)$.

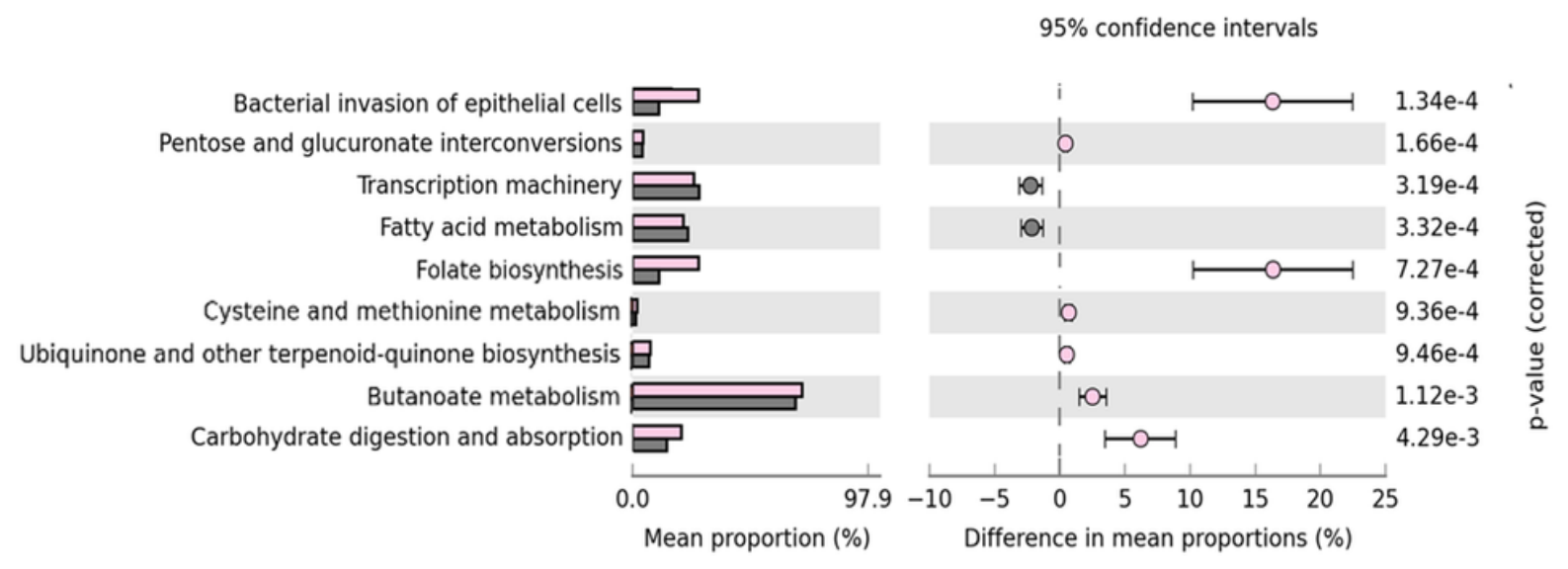

\section{Figure 5}

Microbial metabolic pathways among IgA2+ bacteria are enriched in intestine colonization factors and active carbohydrate metabolism. GO analysis of the most representative metabolic pathways in predicting functional microbial metabolic pathways using PICRUSt analysis (KEGG level three). The abundance of 9 statistically significant metabolic pathways between feces fraction of IgA2+ bacteria, in pink $(n=15)$, and IgA- bacteria in stool samples from children fed with formula, in gray $(n=8)$; from newborn fed with human colostrum for three days). All values are represented as mean \pm standard deviation (SD). 
A

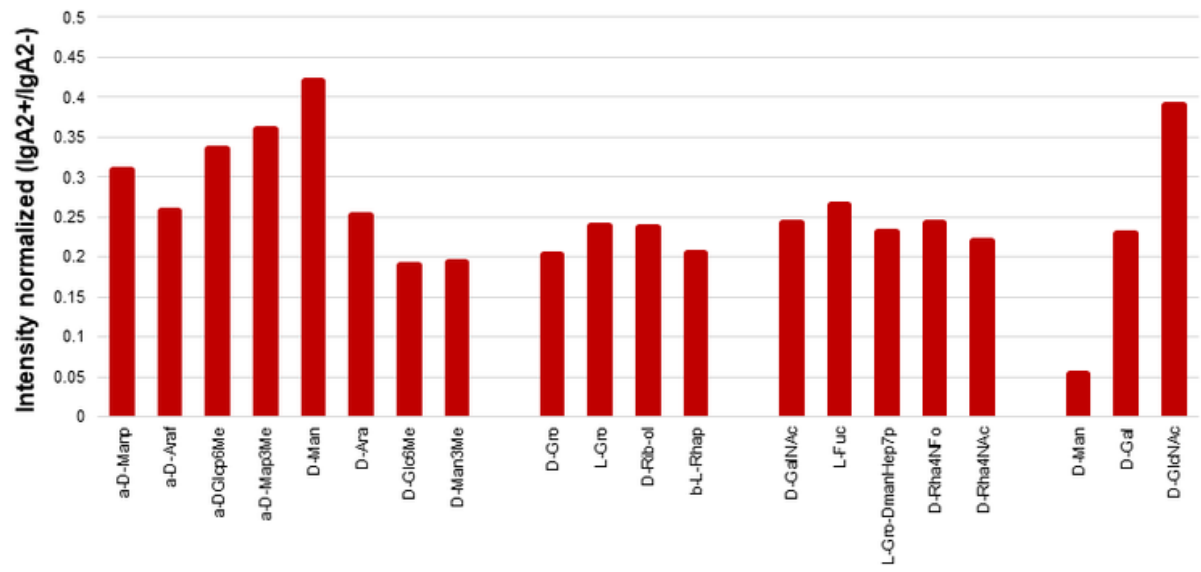

B
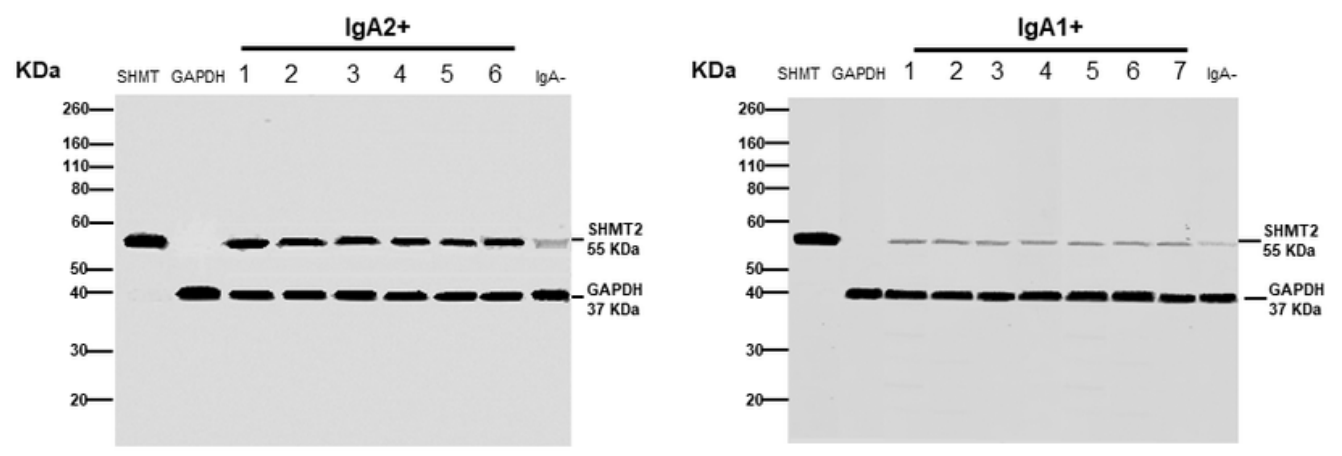

Figure 6

Bacteria association with IgA2 is dependent on glycans/protein recognition. A) Carbohydrate determinants recognized in microarrays by the antibodies in human colostrum. Normalized fluorescent signals from lectin microarray analysis of purified IgA2 associated with bacteria versus IgA2 antibodies not associated with colostrum bacteria $(n=8)$. B) Recognition analysis of IgA subclasses in colostrum to SHMT enzyme. Reactivities of six fractions of cell extracts from lgA2+ (left) bacteria and seven from IgA1+ bacteria (right) from human colostrum, titled with consecutive numbers. SDS-PAGE gels were applied to either western blot to confirm that each protein's comparable amounts were loaded. Data are representative of two or three independent biological experiments.

\section{Supplementary Files}

This is a list of supplementary files associated with this preprint. Click to download.

- Supplementary1.pptx

- Supplementary2.pptx 